Fomicheva, N.M. \& Valuev, D.A. (2021). The connection of times and generations in the restoration of cultural heritage monuments. Culture and arts in the context of cultural heritage. Klironomy, 3 (3), 45-90. HlučínBobrovníky: "Anisiia Tomanek" OSVČ.

Фомичева, Н.М., Валуев, А.А. (2021). Связь времён и поколений в реставрации памятников культурного наследия. Culture and arts in the context of cultural heritage. Klironomy, 3 (3), 45-90. HlučínBobrovníky: "Anisiia Tomanek" OSVČ.

DOI: $10.47451 /$ her2021-10-001

EOI: $10.11249 /$ her2021-10-001

The paper is published in Crossref, Internet Archive, ICI Copernicus, Google Scholar, Academic Resource Index ResearchBib, JGate, ISI, CiteFactor, Journal Factor, eLibrary, Ukrainian National Library databases.

\section{Natalia M. Fomicheva \\ Gilt Restorer of the Highest Category Restorer of Decorative and Applied Art \\ Art Critic, Art Expert \\ Honorary Restorer of St Petersburg \\ Honored Worker of Culture of the Russian Federation \\ St Petersburg, Russia \\ E-mail: natalif47@yandex.ru}

Dmitry A. Valuev

Restorer-sculptor

St Petersburg, Russia

E-mail: v79523528804@yandex.ru

\title{
The connection of times and generations in the restoration of cultural heritage monuments
}

\section{Abstract:}

The topic relevance lies in the fact that the preservation of cultural heritage monuments of our country has been, is and will be the most important at any time for the patriotic, aesthetic, and moral education of young people, who should be instilled with love for the Motherland, for people, who create and preserve beautiful works of art, love of creativity in a variety of fields for contemporaries and descendants. The purpose of the study is to create the Book of Memory of the Restorers of St. Petersburg through the history of the revival of suburban palaces of St Petersburg after the Great Patriotic War on the example of restoring the interiors of the Golden Suite of the Catherine Palace in Tsarskoye Selo and in particular - the Great Hall or the Light Gallery. The article is devoted to the master restorers who recreated from the ruins and ashes the unique interiors of the Catherine Palace of the architectural palace and park reserve Tsarskoye Selo in the city of Pushkin after its destruction during the Second World War. It tells about the continuity of generations of restorers of the 20th and 21 st centuries. In the study course, the works of leading experts and scientists in the field of restoration of the Russian cultural heritage were used. 
Keywords: recreation, conservation, restoration, imitation of gilding by potting and bronzing, Catherine Palace of Tsarskoye Selo, Great Hall, education of the younger generation of restorers, continuity of generations.

\section{Натамия Михаймовна Фомичева} художник-реставратор позолоты высшей категории реставратор произведений АПИ искусствовеА, арт-эксперт Почётный реставратор Санкт-Петербурга

Заслуженный работник культуры РФ Санкт-Петербург, Россия E-mail: natalif47@yandex.ru

Амитрий Алексеевич Ваяуев

Реставратор-лепщик Санкт-Петербург, Россия E-mail: v79523528804@yandex.ru

\section{Связь времён и покомений в реставрации памятников культурного наследия}

\section{Аннотачия:}

Актуальность темы заключается в том, что сохранение памятников культурного наследия

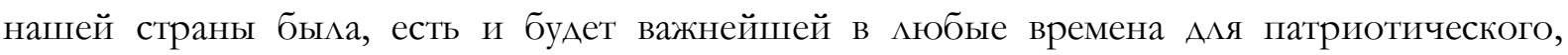
эстетического и нравственного воспитания молодёжи, которой слеАует прививать Родине, к Аюдям, создающим и сохраняющим Аля современников и потомков прекрасные произведения искусства, Аюбовь к творчеству в самых разных областях. Цель исследования - создание «Книги памяти реставраторов Петербурга» через историю возрождения пригородных дворцов Санкт-Петербурга после Великой Отечественной войны на примере восстановления интерьеров Золотой анфилады Екатерининского Аворца в Царском Селе и в частности - Большого зала или Светлой галереи. Статья посвящена мастерамреставраторам, воссоздавшим из руин и пепла уникальные интерьеры Екатерининского Аворца архитектурного дворцово-паркового заповедника Царское Село в городе Пушкине после его разрушений в годы второй мировой войны. В ней рассказывается о преемственности поколений реставраторов XX и XXI веков. В ходе исследования были использованы труды ведущих специалистов и учёных в области реставрации российского культурного наследия.

Ключевые слова: воссоздание, консервация, реставрация, имитация золочения поталью и бронзированием, Екатерининский Аворец Царского Села, Большой зал, воспитание молодого поколения реставраторов, преемственность поколений. 


\section{Introduction}

The topic relevance is based on the fact that the preservation of the cultural heritage monuments of our country has been, is and will be the most important at any time for the patriotic, aesthetic and moral education of young people who should be instilled with love for the Motherland, for people who create and preserve beautiful works of art, love of creativity in a variety of fields for contemporaries and descendants.

The study purpose is to create the Book of Memory of the Restorers of St Petersburg through the history of the revival of suburban palaces of St Petersburg after the Great Patriotic War on the example of restoring the interiors of the Golden Suite of the Catherine Palace in Tsarskoye Selo and in particular - the Great Hall or the Light Gallery. The purpose is to use the examples of the life and work of the departed masters, teach young people to comprehend their secrets of mastery through knowledge of historically professional literature, gaining their own experience when performing conservation and restoration of works of the past using both traditional technologies and materials, and new modern ones, with great care, always remembering the main commandment of the restorer: "Not harm!".

Study tasks are:

- $\quad$ study the history of the revival of suburban palaces of St. Petersburg after the Great Patriotic War, in particular, the Catherine Palace in the city of Pushkin;

- identify and record in the Book of Memory the names of restorers who revived monuments that suffered as a result of the impact of force majeure based on archival materials, memoirs of eyewitnesses and participants of the post-war restoration;

- $\quad$ prepare iconographic material about restorers and their works from the archive and literary sources;

- $\quad$ tell the article readers about the names and numerous professions of restorers who revived from the ashes the masterpieces of Russian suburban architecture of St Petersburg of the 18th and 19th centuries after the Great Patriotic War of 1941-1945.

In this work, historical-archival and comparative-analytical methods were used. They allowed restoring historical justice concerning the search and perpetuation of the memory of the names of master restorers of various professions who selflessly raised the suburban palaces of the golden necklace of the suburbs of Leningrad (St Petersburg) from the ruins after the Second World War. 
The history of the creation of the palace and park ensemble in Tsarskoye Selo, described in the books of G.V. Semenova, M.I. Pylyaev and I.F. Yakovkin, gave a clear idea of the time and people who worked in different periods of history in this wonderful corner of Russia (Antsov, 1908; Semenova, 2009; Fedorova, 2017; Yakovkin, 2008).

Scientific studies of the problems of restoration of the Yekaterinburg Palace in Tsarskoye Selo (and other suburban palaces) were conducted during the reconstruction and restoration of cultural heritage objects destroyed during the war by leading architects and art historians A.A. Kedrinsky, M.G. Kolotov, B.N. Ometov, A.G. Raskin, G.P. Balog, E.S. Gladkova, L.V. Emina, V.V. Lemus and other numerous scientific employees of suburban palaces-museums, the State Inspectorate for the Protection of Monuments, the Museum Funds' Central Repository employees, who returned from evacuation together with objects taken out of museums for a period from 1941 to 1945 (Gladkova et al., 1964; Balog et al., 1972; Balog et al., 1976; Kedrinsky et al., 1983; Kedrinsky et al., 1987; Kedrinsky, 2013; Pyliaev, 2007; Semenova, 2009).

The architects together with the scientific staff of the museum compiled detailed descriptions of the state of the monuments, iconographic materials and documents, historical references revealing the secrets and methods of monuments restoration, thanks to which, in a fairly short time, it was possible to restore monuments that were quickly destroyed under the influence of the unfavourable Leningrad climate and give these works of the past a future.

Books on restoration, creation and decoration of interior decor by such authors as V.L. Antsov, L. Lermontov, K.A. Kaznacheev, V.M. Moiseichev, A.S. Nikolaev, M.K. Nikitin and E.P. Melnikova, A. Reshetnikov, N.Ya. Senatorov, T.S. Fedoseeva, V.V. Filatov, A.M. Shepelev, L.P. Schmidt made it possible to consider technology options and recipes used by masters of the past and present in the field of creation and restoration of works of decorative and applied art, analyze the material and choose the most acceptable ways to finish a replica of the decor of the Great Hall (Antsov, 1908; Kaznacheev, 1890; Lermontov, 1890; Moiseichev, 1957; Nikitin \& Melnikova, 1990; Nikolaev, 1949; Reshetnikov, 1791; Fedoseeva, 1999; Filatov, 1986; Cennini Cennino, 1933; Schmidt, 1909).

In March 2021, Dmitry Valuev, a young man from the restoration college, came to the gilding restorers' workshop at the Cathedral of the Vladimir Icon of the Mother of God, located in the very centre of St Petersburg. The purpose of his visit was to complete a pre-graduate internship and write a final qualifying work. At the first conversation with him, it turned out that he lives in the city of Pushkin, and his thesis 
is devoted to the execution of a replica of the gilded ornamental decor of the Great Hall of the Catherine Palace.

After viewing the text blanks of a college graduate, it became clear that the sources of information on the history of the restoration of the Great Hall are far from complete. It was decided to jointly write a more complete history of the reconstruction of this unique restoration object.

There are enough photographic materials in the personal archive of N.M. Fomicheva and there are enough names of restorers who took part in this grandest work in memory to present the material in chronological order in a coherent manner.

We tried not to forget the representatives of different specialties, since only three artists were mentioned in the materials studied earlier (one of them was Y.A. Kazakov). Of the woodcarvers, only the carver A.K. Kochuev was listed. Behind the scenes, as they say, there were some mythical gilders, since, in the text on the website of Tsarskoye Selo, it was only said that the carving was gilded, and that is it. In short, there were few names there, and there were many gaps in the hall history.

\section{Historical background}

Catherine the First received these lands under the name "Saari Mois" (Saar Manse) in 1710 as a gift from Peter the Great. The first architect of the palace was the German I. Braunstein. The building was founded in 1717 by the Empress order, and later, it was named Catherine. Initially, it was a typical two-story structure "about sixteen bright rooms" in the "Dutch style".

In 1743, Elizabeth Petrovna commissioned Mikhail Zemtsov, Andrei Kvasov and Savva Chevakinsky to improve and expand the palace, and, in 1752, the Empress commissioned Francesco Rastrelli to rebuild the palace, which brought it to a modern look in the Baroque style (Gladkova et al., 1964; Balog et al., 1972; Balog et al., 1976) (Fig. 3).

Previously, the Great Hall was not in the palace. It appeared in place of the light gallery. Its area was about a thousand square meters. The hall was richly decorated with wooden sculptures and carvings, gilded in the technique of combined gilding. It combined glossy and matte areas, making it possible to give the decor liveliness and some romanticism. The sculpture in the hall was outwardly distinguished by a violation of the usual proportions' characteristic of the Baroque style. However, when climbing to a great height, the distortion became imperceptible (Balog et al., 1972) (Fig. 4, 5).

Architect Rastrelli rebuilt the palace as follows: the longitudinal axis of the building became the general spatial coordinate in his plan. The huge length of the 
enfilades is emphasized by the removal of the grand staircase to the south-western end of the building. The variety of the order system, the deep hollows of the windows and the large projections of the colonnades gave a rich play of chiaroscuro, and the multi-coloured facades and the abundance of stucco gave a very solemn and festive look. Gilding on the stucco decoration of the facade of the palace lasted only 30 years, after which it lost its aesthetic appearance, and subsequently, to save money, it began to be painted with golden ochre on drying oil (Balog et al., 1976) (Fig. 1).

Over the creation of the interior of the Great Hall, F. Rastrelli worked from 1752 to 1756 . His assistants at this time were V.I. Neelov and A.I. Mylnikov.

Historically, various types of applied decorative art have been used in the decoration of the Great Hall: modelling, wood carving, painting, gilding. Parquet works, made of valuable "overseas" wood species, were performed in the hall.

Hundreds of serfs of various professions worked simultaneously to create the decor in the Great Hall: carpenters, joiners, parquet workers, sculptors, woodcarvers performed sculptural and ornamental decor from linden wood under the guidance of German master Johann Franz Dunkel. The French gilding master Leprenz worked with Russian gilders. Russian painters painted the ceiling with the famous Italian master decorator Giuseppe Valeriani (Fig. 37).

The sculptural and ornamental carved decor of the Great Hall in the 18thcentury gilders glued three times with bristle brushes with animal skin glue, then pasted the wood joints with a serpin cloth (linen fabric of fine linen weave). After each operation, the surfaces were thoroughly dried before applying a new layer. On the same glue, levkas was prepared by adding the ground chalk to it. Then the soil was also repeatedly applied to the surface of the carved decor with bristle brushes.

The processing of the levkas was conducted in various ways: wet grinding and charging using steel hooks and hog horsetail. A well-polished levkas was made with the help of carved tools, i.e., a drawing was cut through the thickness of the levkas according to the architect's sketch. Then, on smooth surfaces grinding, charging by dry horsetail without gloss was obtained until a porcelain-like surface.

In the 18th century, gilders covered the carved and stucco decor with gold leaf, called "Double". It consisted of the thinnest bimetallic plates, one side of which was silver, and the other was gold. It was done for economic reasons. The metal was obtained by forging two-layer, and because of the silver in its composition cheaper.

In the 19th century, the "double" ceased to be produced, replacing it with a double overlay on the surface first of the lining made of silver, and on top of it gold leaf. 
"Sheet gold, consumed in large quantities, at first wanted to be discharged from the "German lands", but when it turned out that "it is impossible to discharge this gold soon and closer than two years from across the sea", they found "gold leaf" masters in Moscow. The best specialist in the manufacture of gold sheets, thinner than tissue paper, turned out to be a peasant from the village of Pokrovsky near Moscow, Semyon Susalshchikov, who, together with other masters of "goldsmithing", had been harvesting gold leaf for Tsarskoye Selo for many years" (Balog et al., 1972).

There were not enough qualified craftsmen. They were searched for and brought to Tsarskoye Selo from all over the Russian Empire or hired in St. Petersburg "at auction". There were the Petersburg and Kronstadt garrisons' soldiers sent by Decree of Elizabeth Petrovna and various landowners serfs released on rent, monastic peasants and free artisans, who were listed under the jurisdiction of the Office of the Buildings and the Admiralty Board. The working conditions of the forced labourers were extremely difficult: they worked from dawn to dawn for 1214 hours daily without vacations and weekends. In winter, they worked by the light of splinters, ate sparsely, lived in barracks, were deprived of the opportunity to communicate with their families (Baloget al., 1976).

Unable to withstand the most difficult working conditions, craftsmen and builders fled from Tsarskoye Selo, but they were invariably caught, returned, beaten with batogs and put to work again. They were severely punished for escaping so that others would be afraid to escape (Balog et al., 1972).

Russian serf craftsmen also worked on the construction of the palace and interior decoration, and foreign craftsmen passed on their knowledge, skills and experience to inquisitive and talented Russian craftsmen (Gladkova et al., 1964; Baloget al., 1976).

Funds for the palace construction in the state treasury appeared from the Salt Commissariat. The prices of salt in the 18th century were so high that poor peasants could not afford this product, and died of scurvy. Nevertheless, in such a populous country, the treasury received huge revenues from the sale of salt, for which it conducted expensive construction work (Balog et al., 1972).

\section{The Chronicle of the Catherine Palace restoration in the second half of the 20th century or the Book of Memory of Master Restorers}

During the Great Patriotic War, the palace, like the entire architectural ensemble, was looted and destroyed. Before the shelling began, the exhibits were partially sent by echelon to Sarapul and then to Novosibirsk, partially taken to 
Leningrad in the basements of St Isaac's Cathedral. The strongest attacks on the palace were on the night of September 16-17. The shell hit the park and partially destroyed one wall and windows (Fig. 2, 6-10).

As a result of the hostilities, the Great Hall decor was severely damaged, the roof was destroyed, and the hall decoration was exposed to direct long-term effects of atmospheric precipitation. There was a glueing of wood layers from which sculptures and ornamental decor were made. Levkas was stratified, gilding lost its attractiveness, faded, lost the lustre of cast metal and shine. During the war, all the decorations in other halls of the palace suffered, since the direct goal of the fascists was the destruction and looting of all palaces (Fig. 6-10).

Anatoly Mikhailovich Kuchumov headed the search for the exhibits stolen during the occupation years. He travelled to Germany several times. Parquet floors from the Lyon Hall and the Mirror Cabinet were found there. Many stolen exhibits were found in the Estonian settlement Võru. After these searches, many museum items were returned to the Catherine Palace (Fig. 11, 17, 37).

In January 1944, on the second day after the liberation of the city of Pushkin, restoration work already began with the analysis of the palace decoration debris. The Germans left behind mines and eleven aerial bombs connected for the palace explosion and destruction. There was mine clearance work in the parks.

After the war, there were no fully functioning ceilings over the Great Hall. The wooden trusses were badly damaged and needed to be replaced. Metal trusses were manufactured at the Izhora plant in Kolpino. Work on the new farms' installation was conducted with the help of a YAK-24, military helicopter under the command of I.S. Grigoriev on June 17, 1959. Instead of 32 old wooden trusses, 11 metal new ones were installed (Fig. 12-13).

Since 1946, sculptors have been working at the facility, preserving samples of the stucco decoration of facades and interiors as samples for further restoration of the Catherine Palace (Fig. 14-16).

Anatoly Ivanovich Vasiliev's team of plasterers was one of the first to appear at the facility. It recreated the entire plaster layer of the building, both outside and inside. The plasterers' work is very physically difficult. In addition, not every plasterer-builder can be a plasterer-restorer. For these reasons, there have always been few hunters to master this specialty. For several decades, Nikolai Alekseevich Chervyakov and Ivan Nikolaevich Nikolaev worked with Anatoly Ivanovich. Over the years, they have recreated plaster not only in the Pavlovsk and Catherine Palaces but also in all the churches of the Tsarskoye Selo district. The construction work was conducted by pre-war workers of the palace, cadets of the military school, they 
repaired the roof and rafters, the facade was handled by the organization Fasadremstroy, headed by Oleg Osipovich Handelman (Fig. 15).

Since 1957, in the building interiors, the restoration workshops of SNRPM-2 of the Leningrad City Executive Committee have been working. Supervised the work on the 5th precinct of the WORKSHOPS-2, Nikolai an apartment building, a KGB major, retired, then it was replaced by Vasily Yegorovich Nikonov, who worked in Medyntseva foreman (Fig. 14).

The hard work and talent of a big team of restorers of up to four hundred people daily who worked in the Palace made possible from the ashes and debris.

The Great Hall, a masterpiece of Russian Baroque, with an area of about 1000 sq. m. meters is one of the largest halls in Europe in this style, required a lot of effort, labour and time to recreate it. The comprehensive restoration of the Great Hall took almost two decades, and its decoration was completed only in 1985 (Fig. 38-39).

Architect Alexander Alexandrovich Kedrinsky and his assistants led the work on the reconstruction and restoration of the Catherine Palace. The sculpture was restored by the sculptor Lilia Mikhailovna Shvetskaya and the woodcarvers themselves since there was such an abundance of sculpture in the Great Hall that one sculptor could not cope with physically quickly, skilled hands of specialists were also needed. All the carvers who were older in age and work experience could perfectly sculpt models and their lost missing fragments, which they successfully completed in full together with L.M. Shvetskoy for all the palace halls of Rastrelli's Golden Suite (Kedrinsky et al., 1983; Kedrinsky et al., 1987; Kedrinsky, 2013; Semenova, 2009) (Fig. 29-32, 34-37).

Yakov Alexandrovich Kazakov's brigade painters made the ceiling of the Great Hall, called The Triumph of Russia. The artists first sketched the ceiling in scale, approved it at the restoration council. Then they made sketches of individual parts of the ceiling in full size, translated the drawings into tracing paper, then onto cardboard, found a colour solution and only after that did the work on canvas. At the same time, up to eighteen people worked in the team of painters. The main team consisted of painters Samuel Fedorovich Konenkov, Vitaly Gennadievich Zhuravlev, Boris Nikolaevich Lebedev, Yuri Fedorovich Shitov, Anatoly Ivanovich Burenin, Nikolai Fedorovich Anisimov, Ivan Orestovich Alekseev. There were two young artists: Armen (Surenovich) Gaziyants and Boris Golovanov. (Somehow, it was not accepted in this brigade to accept young people into the team). (Fig. 19-21, 27, 37).

The central part of the plafond Triumph of Russia, made by V.I. Shebuyev in the 19th century after a major fire, and lost during the war, was recreated anew, and two 
side fragments of the plafond (found in Mikhailovsky Castle) were returned to Pushkin, restored and attached to historical sites.

Around the three picturesque inserts, the ceiling architectural part was painted directly on the plaster, on which the columns were designed for perspective and the vanishing point located in the centre of the hall, this effect, when moving to the centre, the columns straightened, and the hall seemed to become higher (Fig. 19, 21).

Anatoly Burmanov's carpenters team attached wooden bars (logs) to brick walls, on which shields with sculptural and ornamental decor were subsequently attached. A team of carpenters led by Alexey Ivanovich Berezkin made shields and mounted ornamental sculptures and carvings on them. Machine operator Alexander Vasilyevich Suvorov glued multilayer blanks from dried and stitched linden boards to perform sculptural decoration: caryatids, female sculptures and putti.

After installing the billboards in the hall, a team of painters, headed by Pyotr Semenovich Vybornov, dried, putty and painted them with oil matte white paint. Such masters as Pyotr Fedorovich Lunev and Alexey Mikhailovich Kryukov worked with him together. In addition to them, vocational schools' graduates, mostly girls, who, thanks to their personal and business qualities, such as accuracy and diligence, gradually joined the ranks of gilders, were constantly working in the team of painters. It is noteworthy that Peter Fedorovich Lunev, being a very colourful figure, served as a model for the restorers to create one of the images on the central canvas Triumph of Russia.

Restoration and decoration of the compositions of the Great Hall were previously conducted in the premises of the second and third Anti-Chambers, where restoration workshops of woodcarvers and gilders were temporarily located (Balog et al., 1976).

The restoration of the carved sculptural and ornamental decor was conducted by five teams totalling up to 60 people.

Alexey Konstantinovich Kochuev was the founder of the conservation and restoration of wood carvings. Anatoly Vasilyevich Vinogradov and Viktor Alekseevich Bogdanov worked alongside him. All of them were graduates of the V.I. Mukhina Art and Industrial College. Yuri Mikhailovich Kozlov and Oleg Fedorovich Timofeev headed two more brigades, and the youth brigade of graduates of the restoration lyceum was headed by a young woodcarver Vladimir Konstantinovich Chekushin (Fig. 22, 23, 28, 37).

In different years, Konstantin Dmitrievich Maurichev, Galina Andreevna Maslova, Yanina Andreevna Kaplyuk and Natalia Mikhailovna Fomicheva, who in 1979 headed the largest youth gilding team of Restorer LLC numbering 25 people, 
led the work on gilding carvings and sculptures. At the end of 1979, a small gilders' separate team of 7 people under the leadership of Galina Arsentievna Siverina joined them (Fig. 24-26).

When gilding the sculpture and ornamental decor, combined gilding of works made of wood combined by high-gloss gilding on a polymer and matte according to ancient technologies of the 18th century was conducted. Modern gilding masters performed glossy gilding on a polymer with "heavy" gold leaf (the weight of the book is 2.5 grams), with a much larger thickness of leaves than on matte background areas where "light" gold was used (1.25 grams in the book). After a short time after being applied to certain areas of the surface of the part, the gold was carefully and carefully polished with agate teeth until the appearance of the appearance and characteristic gloss of cast metal on it. In the old days, a tooth of a meat-eating animal with a good strong enamel was used to polish gold. Draperies imitating fabric were gilded on the ground of the polymer, and all the protruding places were on the relief: shell lapels, staples, beans, cartouches, plaques. After polishing with teeth, these relief areas stood out with a specific gloss.

The rest of the surface of the parts, with the coating applied to it, was subject to matte gilding. The surfaces for this type of gilding were tinted with light ochre, then glued with an aqueous solution of mezdra (natural skin) glue, dried well, moistened with an allowance and gold leaf was applied, pressing it to the surface with a small cotton swab. (In the old days, the role of cotton wool was performed by a hare's paw).

After a little drying of this surface, the gold was wiped with cotton wool, and the gaps and breaks of gold were corrected in the same way. What was applied before? At the end of the matte gilding and good drying of the surface, it was covered with a special matte solution to enhance the contrast between the two types of gilding.

When gilding the decor of the Great Hall during its reconstruction, 7.7 kilograms of gold leaf were used.

A large team of sculptors, who simultaneously worked to create girandoles, lighting eleven horn devices, the entire Golden Enfilade of Rastrelli, recreated the floral-stylized ornament in the Baroque of all the fine plastics of wall panels, damask frames, window and door openings. At that time, Faina Alexandrovna Lebedeva headed the sculptors' team (Fig. 18).

A team of coiners, led by Vasily Alekseevich Maryutin, made metal sockets for girandoles. Pavel Semenovich Ryzhkov and Evgeny Nikolaevich Pukhov did the work to equip electricity on the girandoles. 
Parquet of the Large Hall, with an area of almost 1000 sq. m. meters, recreated by the team of Evgeny Fedorovich Kudryashov.

On July 10, 1980, the Grand Throne Hall was opened, timed to coincide with the beginning of the Moscow Olympiad (Fig. 38, 39).

Rastrelli's golden suite was partially restored only in 1960-80. At the moment, restoration work in the palace is still underway in the rooms of Empress Catherine the Second in the Zubovsky Building.

The time of D. Valuev's pre-graduate internship in restoration workshops flew by quickly, as all process participants were engaged in interesting research and useful practical work.

As a result of D. Valuev's research and theoretical work, an initial list of master restorers, who took part in this grandiose project to recreate the stucco, sculptural and ornamental carved gilded decor of the Catherine Palace's Great Hall has been obtained, which has yet to be continued when collecting archival documents and iconographic materials, was completed.

Thus, a good start was made to great research work to create the Book of Memory of Master Restorers, which is very important both for the continuity of generations and especially for young restorers of different professions who decided to devote their lives to this noble cause - the preservation of monuments of the historical past of our Motherland.

\section{Creating a replica of a baroque stylized ornament}

Any restoration project begins to create a graphic image on paper of the ideas of the author of this project, first in general terms. Then in specific details with dimensions in scale and full size. So, it was before, and so it is now. After receiving the working drawing, the sculptor-modeller proceeds to create a life-size volumetric model, making it out of soft material - plasticine. It is easiest to correct and refine the heights and volumes of the executed ornament or sculpture.

When making a large-sized model, a base is made for it, e.g., from wood, to reduce the plasticine consumption to apply it on substrate top, and create relief and the desired shape by such type.

When making a model in a soft material, various tools and devices are used: stacks, knives to make it as clean as possible. Stacks are usually made of metal or wood with metal tips - loops of strong wire or strips of sharpened steel. The wood for the stacks is taken solid: beech, palm, lilac, maple.

After the soft model is approved by the restoration council, the part is transferred to plaster through the creation of a mold for further work, e.g., for wood 
carving. It is done because, during further work, plasticine can easily deform, and the model will deteriorate, while gypsum is less susceptible to damage.

Previously, there were several ways of making molds from carpentry glue. In the manufacture of the adhesive mold, the wall thickness was made from 5 to 25 $\mathrm{mm}$. The glue molds were short-lived, as they quickly wore out. Their life lasted for several days, as the glue with gelatin dried, hardened, lost their relief and shape. Unsuitable forms were replaced with new ones. In the work, 8-15 forms were used simultaneously for small parts and from 2 to 5 for large ones. The gypsum in them needed to have time to cool down during the casting. The used molds were washed and worked with them again (Bolshakov, 1948; Senatorov et al., 1982; Fedoseeva, 1999).

Later, they began to make molds from formoplast. This mold has many advantages compared to the adhesive one: it is more durable since it does not lose its shape: up to 1000 high-quality parts can be cast from it. It is also done with a casing with a wall thickness of about 15-25 mm. Glue and mastic molds were made twice. After the first molding and casting, the gypsum part was refined, molded and cast again.

Over time, molding materials became more practical, they were made of vixint, compound and silicone. The compositions were two- or three-component. Plastic and silicone molds could be made at one time, provided that the model was made well. Nowadays, molds are made of silicone with a catalyst - a new molding material used to improve the quality and quantity of castings, greatly facilitating the laborious work of the modeller.

If necessary, reinforcement was carried out during casting - strengthening the strength of the product by introducing reinforcement or similar materials into it (wood, hemp, twine, plaster shingles).

When working with gypsum, various blades and plasters are used for mixing and applying it, that is, containers for mixing it. Gypsum plasters can be rubber or plastic. Their main quality is to be well cleaned of gypsum. So, they are made of a sufficiently flexible material so that this process is easy, even if the gypsum inside hardens (Bolshakov, 1948; Fedoseeva, 1999; Shepelev, 1992).

The backside of the part should be flat so that when it is mounted to the surface, it fits flat against it, and there would be no need to lubricate the plaster under it. While the plaster is not frozen, it is smoothed with a spatula to do it. They were impregnated with hot natural drying oil with bristle brushes to give strength to gypsum parts. Excess drying oil was removed from the plaster surface with a rag to prevent smudges. Drying oil made it possible to fix the gypsum surface, increased 
the service life of the part, making it more durable. This layer was very well dried Bolshakov, 1948; Senatorov et al., 1982).

The production of the Baroque ornament began in the Catherine Palace in the great hall with the photo fixation of the original. The frames were made from several angles to understand and clarify the height of the relief of the ornament. Usually, a scale ruler is placed next to it to show the part dimensions, but in this case, this is unacceptable, since the work was conducted with a museum exhibit that cannot be touched, with much fewer objects (Fig. 40-42).

It was necessary to make a frame of the front side so that the detail was completely visible, and there should not be unnecessary objects in the frame. It was not possible to do it with this detail, since it is located in a corner. It is impossible to photograph it directly, and so the ornament of the neighbouring part does not interfere.

After the photo fixation, the best frame of the front side of the part, printed in the required format (in our case, $50 \times 70 \mathrm{~cm}$ ), was selected. It was made in black and white and translated into a graphic on paper. Then the graphic image of the part was fixed on the tablet. The edges of the sheet were neatly bent from four sides; the surface was smoothed. On the reverse side, the sheet was attached to the tablet using buttons. First, the corners were fixed, and several buttons' pieces were on all sides (Fig. 43).

The workplace was organized such that the direct work was conducted as comfortably as possible. First of all, a wooden table with a smooth edge was needed. A flat edge is required to pull the rods, and it should be wooden so that nails can be driven in there. On the same table (based on the fact that it is clean), all operations were performed: modelling, casting, etc. There was always a trash bucket and a bucket of water next to the table. Order and cleanliness were always maintained on the table: all tools were put in their places after use, materials were treated similarly. After each operation, the table was cleaned and wiped. If the plaster was frozen on the table, it was scraped off with a spatula. It was important to keep the workplace clean and tidy to know where what materials and tools are located, and so that they do not interfere with work (Fig. 44-45).

If there are gypsum rods in the detail, you need to pull them out in advance before you start creating a form in a soft material and sculpt on top of them. This way, the form will be more accurate and correct.

The manufacture of rods began with the creation of a profile. It should know the size and shape of the gypsum traction like the architectural fragments that are 
used there for it. Draft height, width measurements and the architectural fragments' dimensions were conducted (Shepelev, 1992).

Next, a metal plate (usually aluminium) of the required size was taken, and the thrust profile was marked with it on a scale (1:1). The profile is cut with scissors on metal. Architectural fragments are made by fillets, right angles - triangular and square, rollers - rounded. The profile should be made as accurate as possible, since the thrust radius, accuracy and purity of the work itself depend on it (Fig. 53-55).

After creating a profile, you need to assemble a template. It consists of planks and bars connected. Before starting work, all the wooden parts of the template are drilled, made as smooth and straight as possible, and the chamfer is removed from them. It is done so as not to cut yourself or damage your hands while working (Fig. 53).

First of all, a rectangular wooden piece is taken, a template is marked on its long side so that it is at the very edge. It is cut in such a way that the metal template completely covers the tree, and it was not visible from the front side. The chamfer is removed from the back of the wooden part. Next, the template is nailed to the part with nails, which are bent and skinned for safety purposes.

Next, the same wooden rectangular part is taken. They are both fastened together with a screwdriver and screws. If necessary, before this, a master can drill a hole so that the screws come in easier. The parts are screwed so that they form the letter "T". Moreover, the part with the profile should be attached to the middle of another part.

Then, to strengthen the structure, two bars of the same size are taken. They need to be fixed so that they connect the part with the profile on both sides. To do this, you need to cut off the extreme parts so that a smooth face is formed, which will be adjacent to the tree. They are also attached with screws and a screwdriver (Fig. 53-54)

Then another rectangular wooden piece is taken, which were used earlier. It is attached to the one on which there is no profile, half below it, and it is also attached to screws. This part is a guide. It serves so that the template attached to the table edge can be moved along the edge. The final stage at this stage will be chamfering on the template. The profile is ready. Now the rods are being pulled (Shepelev, 1992) (Fig. 55).

To do this, you need a table with a straight edge. We attach a template to it and mark where the thrust will take place. Then, following the movement of the traction, we drive nails to a height slightly less than the highest place at the template and be 
sure to cut off the hats so that the traction can be removed, otherwise, the plaster will grab the hats, and the traction can be broken at the same time.

Immediately, before pulling the rods, you need to pour oil on the place where the plaster will be applied so that the rods can be removed. After that, we dilute the plaster. It needs to be mixed thicker than for fillings. Now we put the template to the table edge, pour the plaster under the profile and pull it to the pull end, then remove the template, put it at the beginning and repeat the operation. It is necessary to gradually pour the plaster under the template and carry it out as many times as possible, for greater clarity of forms. Repeat the operation until the thrust becomes the right size, and the entire profile is filled with plaster.

It should try to pick up excess gypsum and apply them under the profile to save money during the process. You should also clean the template from the hardening plaster as often as possible, as it can damage the shape of the template and spoil all the traction. After the rods are pulled out, they should dry for several hours, up to a day. Next, the rods are skinned and defects are corrected. After that, they can be mounted in place (Fig. 55).

To do it, liquid gypsum is diluted, applied to the draft and immediately you need to apply the draft to the surface, then wait for the gypsum to "stand up". If necessary, it can be fine-anointed after that.

Next comes one of the most significant and responsible stages of the work - to create a form in a soft material. On top of the graphic drawing and the attached rods, we begin applying plasticine focusing on the image contour and inside it. Next, we increase the mass in height where it is necessary, checking with photos in oblique light. When working, we use different stacks to smooth the plasticine and give it the desired shape and with knives to cut off the excess. Constantly checking the photos, we make the main relief details, stylized acanthus leaves (Fig. 46).

After making a model in plasticine, it is necessary to make a pre-selection, i.e., remove lumps of plasticine, align it, seal up breakthroughs, add the model with loops and stacks. In particular, you need to be attentive to the front side, since it is mainly the viewer who will see it but do not forget about the ends because they are often uneven due to the imposition of several layers of plasticine and less attention to them (Fig. 47).

This model should be made as clean as possible, with the least number of defects, because at this work stage, it is easy to fix them and, in the future, it will be more difficult (Senatorov et al., 1982).

Next, it should proceed to the molding. To do it, the model in a soft material must be coated 2-3 times with an alcoholic solution of shellac so that the silicone 
mold can be easily removed from it then. Dry each coat of varnish for at least an hour. (Fig. 48, 49).

Next, plasticine is taken and a small wall is made at a distance from the modela fence made of plastic or thin tin so that the silicone does not leak out when pouring. Silicon is mixed with the hardener in the proportion indicated on the package and stirred until a homogeneous composition is obtained. It should mix them very carefully otherwise the silicone will not harden. Next, you need to carefully pour this composition into the model and try getting it into all the tiny cracks. After that, it should take a brush and fine-anoint silicone from the recesses of the relief on its elevation. It should be done until the silicone begins to thicken. At this point, you need to stop the operation and carefully examine the result. If it is positive, it should stop the work for a day to harden the silicone. However, if plasticine is still visible somewhere, you need to dilute some more silicone and fine-anoint these identified places with it, then wash the brush with solvent, and then with baby soap with warm water. After achieving a satisfactory result, leave the model for a day for the final hardening of the silicone (Fig. 48-49).

After a day, you need to carefully remove the sides of the plasticine fences and make a plaster casing. Its purpose is to maintain the silicone mold so that it does not distort during operation. The casing is made of gypsum: it is diluted a little thicker than usual, and wait until it begins to set. In a creamy form, it is applied to a silicone mold and levelled, after which it is left to dry completely.

After the casing has finally dried and frozen, it is carefully removed so as not to damage it. Pry the edges of the casing with a spatula, and set them aside. After that, you can already remove the silicone mold. At the same time, it is gently pulled from several sides until it comes out. If desired, it can trim the edges with a scalpel for a more aesthetic appearance. After that, it is put back into the plaster casing. The silicone mold for castings is ready (Fig. 50).

Then the casting of gypsum is made directly. A container with clean water is taken and gypsum (white fine-grained powder of the G-17 brand) is added there. Gypsum is necessarily added to the water, and not vice versa, since lumps form when the reverse action occurs. The solution is thoroughly mixed to a homogeneous mass, after which you need to tap lightly on the sides of the container to release air. This is done so that no bubbles form in the plaster and, consequently, the structure is more durable. Only after all of the above operations, gypsum can be poured into the mold. You need to fill it carefully and make sure that the plaster falls into all the recesses of the reliefs of the form. It is necessary to pour gypsum while it is still liquid and has not begun to set, otherwise, it will not repeat the shape so accurately. If possible, 
you also need to tap lightly on the casing and mold to release bubbles, as is done when mixing gypsum (Shepelev, 1992).

It is necessary to conduct the filling on a flat surface so that the backside of the part is flat and can be mounted on a flat surface. To achieve a flat surface, you can pass with a wide spatula. If there are particularly thin places on the parts that can break in plaster. Then they can be strengthened, i.e., reinforced by laying reinforcement in a liquid composition in the reinforcement form. After casting, the part must be left for some time for the gypsum to dry completely for about a day (Fig. 52).

After the plaster has hardened, the part can be removed. To do this, first, remove the silicone mold together with the gypsum casting from the casing. After that, they begin carefully removing the silicone. It should be done with extreme caution, because if you pull the silicone too hard, it can break the gypsum casting, especially in thin places. It should be removed from thin and fragile places to thickened and durable ones to increase the likelihood that the part will not break, crack or split (Shepelev, 1992).

The execution of the object in a soft material took the most time. In the work process, difficulties arose in determining the height of the relief and individual elements of the ornament because the work was conducted according to the photo, and not next to the product that served as a standard but, during a long, unhurried modelling process, these tasks were solved.

In the modelling process, the tools were also updated to better ones. They helped to achieve forms' smoothness and accuracy like to make the decoration on the ornament surface: stylized shells, leaves and flowers.

At the same stage, the rods were pulled out of gypsum. It was done using a metal profile fixed to the template. The rods had to be pulled out and installed before creating the model in a soft material so that it would be easier to repeat the ornament superimposed on the rods. However, with good work with the mold, they could be installed after molding (Bolshakov, 1948) (Fig. 56-57).

As opposed to modelling, molding turned out to be the fastest process of all. It was conducted after the approval of the head of the diploma and under his supervision in the workshop. The molding of the model was carried out in a spread in two stages: stage 1 - the main silicone filling, stage 2 - greasing heights. The plaster casing was applied and removed after the silicone had completely dried. The alignment of the casing was conducted with a spatula.

The casting was not entirely successful, as the part after being removed from the mold cracked in several places due to the complexity and different heights of its 
shape. Then it was glued to the tablet, and all the chip places were greased with gypsum mortar. (Fig. 51, 52).

In restoration, two castings are always conducted: a rough one to finalize all defects in plaster and a finishing one from a modified plaster model. In this case, the second one was not conducted to save the budget, and since the form itself turned out well. The plaster casting turned out without bubbles and huge defects of the ornament, only a tiny modification of the shape was required: grinding and greasing. Before installing the ornament in a permanent place, it is desirable to eliminate all minor defects, make a fine-anointing and skinning, since then it will be more difficult to do.

There are two types of fine-anointing. The place of work is wetted with water. It is done so that the already frozen gypsum does not absorb the water of the newly applied composition. Otherwise, the putty will fail and fall off. Then the plaster is diluted. Before applying, you need to wait until it starts to set so that it is thicker (like sour cream). Next, with a stack or other convenient tool, it should apply the thickened plaster to the right place and give us the shape we need. This spread type is used when restoring a large volume, e.g., an entire part or a part (Senatorov et al., 1982; Shepelev, 1992).

The place of work, as well as in the first case, is moistened with water. We breed gypsum. We take a brush and use it to apply plaster on the loss in layers. It is significant to monitor the humidity and wet the surface if it is dry. This method is better to use with small chips or cuts, it takes longer, since the work goes in layers, but it turns out to be of higher quality. At the end of the process, it is necessary to thoroughly wash the brush with baby soap and warm water to clean it from plaster so it will last longer.

Both types of putty are used equally often and which of them to use when is not significant. It depends rather on the master and how it is more convenient to work. If necessary, skinning is conducted after the putty.

If the detail is split or some part is broken off, then they are fastened with plaster. To do it, notches are applied on both sides. Then they are slightly moistened with water, gypsum is diluted, more liquid than usual, and applied to one of the parts, after which they are immediately connected and held for a while until the gypsum more or less rises. Then it should cover up the joint. To do this, they also dilute a little liquid gypsum and fill the gap with it until it is flooded, after which the surface is leveled, and after drying it is skinned.

After performing all of the above operations and a flat backside, when all the parts are in place, skinned and greased, you can mount them on a tablet. To do it, 
notches are made on the detail in one direction and on the surface to which they will be mounted. For convenience, the part is applied to the surface and outlined to know exactly where it needs to be placed. Wet the part. Dilute a little liquid gypsum, apply it in an even layer on the entire back surface of the part and immediately apply it to the surface. So, it needs to be held for a while so that the plaster "grabs". If necessary, you can put the part under the load in the form of sandbags, but not too heavy so as not to break it. Now you need to wait until the plaster seizes, and the part will be thoroughly fixed (Bolshakov, 1948; Shepelev, 1992) (Fig. 56-57).

After the part is fixed, you need to carefully inspect it for the presence of chips, cracks, defects and see if it fits snugly to the surface everywhere. Specific attention should be paid to the front side and particularly expressive elements since it is on them that the eye will be directed first of all. If the part lags behind the surface in some places, then this place needs to be greased. In this case, you can use a syringe: the surface is moistened with water, a little liquid gypsum is diluted, which is typed into the syringe, after which it is injected into the required place. Or, if the syringe does not work, you can use a stack or a small shovel. Also, if some plaster ornament places are not satisfied with the quality, they can be redone by spreading plaster on top and giving the product the desired shape.

Gypsum is amenable to processing. Therefore, if you need to clarify the shape, boundaries or reduce some elements, you can simply cut it with a scalpel. But this is only on condition that the plaster was not too thick. Otherwise, it will be harder and, when working on it with carved tools, the result will be worse, and the tools will be blunted ahead of time.

The final stage of working with the form is skinning. To do it, the sandpaper of different grain sizes is taken, and the part is skinned: first a huge, then a medium and then a tiny skin. You can only skin flat surfaces, and those, which the carpet is located cannot be touched on, as this will spoil it (Fig. 57).

After we have made sure that the part is cleaned, has no flaws and defects and is firmly fixed on the surface, we can proceed to finish.

\section{Gilding imitation of two types on baroque ornament replica with a plaster base. The technology of ornamental decor finishing replicas in the imitation gilding form of two types (glossy and matte)}

The study of specific literature on the decoration of decorative plaster products, from the 18th century to the present day (Antsov, 1908; Kaznacheev, 1890; Lermontov, 1890; Moiseichev, 1957; Nikitin \& Melnikova, 1990; Nikolaev, 1949; 
Fedoseeva, 1999; Filatov, 1986; Cennini Cennino, 1933; Shepelev, 1992; Schmidt, 1909).

Careful detail's surface skinning intended to simulate gilding with potal was conducted using a water-resistant emery cloth from Mirca No. 180, 240, 320. After that, a thorough surface dusting was conducted with a vacuum cleaner and a bristle brush (Fig. 57).

A long-term operation was the decorative finishing execution because it was very dependent on the drying time of the varnishes, and the microclimate in the workshop accordingly. Varnishes dried for a very long time and had to wait.

Applying a coloured lining (primer-polymer) to the areas of imitation of glossy gilding with a soft squirrel brush in two layers without gaps and gaps to obtain a smooth matte surface of the lining. At first, the glossy gilding imitation places were passed with a primer-polymer. It was necessary to obtain a better gloss. Then the areas' surface was covered with oil varnish, and a potal was already applied to it, which was lapped with a cotton swab so that it had an even greater shine (Fig. 58).

Application of DUX quick-drying oil varnish (1-3 hours) with a synthetic brush with a spatula No. 8 in a thin, even layer. The first layer was dried for 24 hours. The second layer of varnish was dried until the appearance of a working peeling off, upon reaching which a potal strophe was applied, pressed against the surface with a cotton swab of medium size and density. Then the potal was lapped to the lacquer surface with the same swab in circular movements from the centre to the edges of the strophe until it looked like a glossy metal. Thus, work was conducted on all sites intended for this type of work (Fig. 59-60).

The alcohol shellac varnish application was conducted in all areas where the polishing was previously performed. Alcohol shellac varnish of $15 \%$ concentration was applied in two layers with the drying of each layer for 3-5 hours. In nasty areas, the varnish was sanded with a water-resistant sandpaper No. 1000, after which the surface was thoroughly dusted with a vacuum cleaner and a brush.

The matte gilding imitation by the method of bronzing on the oil varnish was performed after the alcohol shellac varnish had dried (Fig. 61).

All the detail's parts intended to simulate matte gilding were coated with DUX oil varnish with a quick-drying (1-3 hours) thin, even layer. After 40 minutes, the varnish reached the working peeling off, and bronze powder was applied to its surface with a soft brush, also in a thin, even layer.

After drying the oil varnish, a day later, with the help of a vacuum cleaner, the excess bronze powder was removed and the necessary adjustments were made to the surface of the finish in places of small gaps in the varnish (Fig. 62, 63). 
In this form, the detail was left to dry for 24 hours. Then the excess bronze powder that did not stick to the varnish was vacuumed with extreme care so as not to damage the fresh surface of the decorative coating.

Fixing the detail's surface finish with aerosol hairspray in areas of two types of imitation gilding (glossy and matte) was conducted at a distance of $30-40 \mathrm{~cm}$ from the detail to prevent further oxidation of the decorative imitating gilding coating during operation. When spraying the fixing varnish, it was impossible to allow smudges or omissions.

Background areas painting of stucco decoration by highlighting its elements with colour on the tablet were conducted in stages.

24 hours after finishing the decorative finishing of the plaster detail, the background areas were soaked with natural linseed oil slightly heated in a water bath, diluted with white spirit (1:1). Drying of this layer was conducted at a constant air temperature in the workshop room $+23.5^{\circ} \mathrm{C}$ for two days.

The background areas' colouring finishing layer was made with high-quality white water-based emulsion paint using a synthetic hair brush with great care so as not to damage the decorative coating of the part (Fig. 64).

\section{Conclusion}

The collection of information on the object intended for the final qualification work completion began in the Catherine Palace directly in the Great Hall from a conversation with the caretaker and the guide helped determine the location of the desired ornamental decoration detail.

Familiarization with the history of the construction and reconstruction of the palace itself became known from books. The most interesting historical materials were obtained from a book written by several researchers of the Catherine Palace named Pushkin Museums and Parks. Information about the revival and restoration of the palace after the Second World War became known from the story of the artistrestorer of gilding of the highest category, who worked in this hall from the very beginning to the end of its restoration, and directly the master of industrial training, who conducted pre-graduate practice.

Information on ancient technologies of making decorative works in the interiors of palaces and their decoration was revealed in numerous sources of the 19th and 20th centuries, reflecting the work of Russian woodcarvers, modellers, gilders, who created these interiors under the guidance of sculptors and architects.

The search for information on the ancient technology of creating plaster parts and their finishes, which were also taken from books, was worth some work. This 
information was necessary since the restoration and replica must be made from the same materials and using the same technologies, which they were created in the past.

However, when performing the practical part of the work, the basic and its finishing material was changed compared to the original for objective reasons. The original detail in the hall is made in the wood carving technique and decorated with combined gilding on the levkas with the matting execution on the matte gilding areas. The replica had to be made in a different base material and a different finishing technology, different from the historical finish of the original. It was decided to create a gypsum replica with imitation gilding, using other materials in the work decoration: sheet metal on glossy areas and bronze powder on matte ones.

The decorative finishing of the replica was busy and very dependent on the drying time of the varnishes and the microclimate in the workshop. Following the plan drawn up earlier, the tasks were successfully completed, and the study purpose was achieved.

Thus, the practical part of D. Valuev's work on creating a replica of the ornamental decor of the Great Hall in other materials of the foundation and its decoration, different from the original of the monument, did not worsen the final result at all but gave a new experience in the work of a young specialist. He independently completed the entire cycle of stucco work and mastered the methods of finishing the stucco decoration in the form of imitation gilding by potting on glossy areas and by bronzing - on background areas.

\section{References:}

Antsov, V.L. (1908). Gilding and silvering on wood and metal. St Petersburg: M.P. Petrov Publishing house under the A.F. Sukhov Firm. (in Russian)

Balog, G.P., Gladkova, E.S., Emina, L.V., \& Lemus, V.V. (1972). Pushkin museums and parks. Travel guide. Leningrad: Lenizdat. (in Russian)

Balog, G.P., Gladkova, E.S., Emina, L.V., \& Lemus, V.V. (1976). Pushkin nuseums and parks. Travel guide. Leningrad: Lenizdat. (in Russian)

Bolshakov, A.M. (1948). Stucco works. Molding, casting and setting of stucco products. Moscow, Leningrad: State Architectural Publishing House. (in Russian)

Cennini Cennino (1933). A treatise on painting. Moscow, Leningrad: OGIZ, IZOGIZ. (in Russian)

Fedorova, Z.M. (2017). Our destinies were determined by time. Memories of the woodcarver V.A. Afonichev. St Petersburg, Pavlovsk. (in Russian)

Fedoseeva, T.S. (1999). Materials for restorers. Lectures. Moscow: GosNIIR. (in Russian) 
Filatov, V.V. (1986). Restoration of easel tempera painting. Moscow: Fine Arts. (in Russian)

Gladkova, E.S., Emina, L.V., \& Lemus, V.V. (1964). Museums and parks in Pushkin. Travel guide. Leningrad: Lenizdat. (in Russian)

Kaznacheev, K.A. (1890). Gilding and silvering of wooden products. Moscow: Kaznacheev. (in Russian)

Kedrinsky, A.A. (2013). The Great Tsarskoye Selo (Catherine) Palace. From a suburban estate to a ceremonial residence. 1710-1760. St Petersburg: Historical Illustration. (in Russian)

Kedrinsky A.A., Kolotov, M.G., Ometov, B.N., \& Raskin, A.G. (1983). Restoration of Leningrad architectural monuments. Leningrad: Stroyizdat. (in Russian)

Kedrinsky, A.A., Kolotov, M.G., Ometov, B.N., \& Raskin, A.G. (1987). Restoration of Leningrad architectural monuments. Leningrad: Stroyizdat. (in Russian)

Lermontov, V. (1890). Gilding and silvering of wooden products. Moscow: Craft Newspaper Edition. (in Russian)

Moiseichev, V.M. (1957). The work of a master gilder. Leningrad: Gosstroyizdat. (in Russian)

Nikitin, M.K. \& Melnikova, E.P. (1990). Chemistry in restoration. Moscow: Chemistry. (in Russian)

Nikolaev, A.S. (1949). Works of a gilder. Leningrad, Moscow: State Architectural Publishing House. (in Russian)

Pyliaev, M.I. (2007). Old Petersburg. Stories from the former life of the capital. St Petersburg: Parity. (in Russian)

Reshetnikov, A. (1791). A curious artist and craftsman. Moscow. (in Russian)

Semenova, G.V. (2009). Tsarskoye Selo is familiar and unfamiliar. Moscow, St Petersburg: Tsentrpoligraf. (in Russian)

Senatorov, N.Y., Korshunova A.P., \& Mushtayeva N.E. (1982). Stucco works: A textbook for secondary vocational schools. 2nd edition. Moscow: High School. (in Russian)

Shepelev, A.M. (1992). Modelling in the house and apartment. Reference manual. Moscow: Stroyizdat. (in Russian)

Schmidt, L.P. (1909). Gilding, silvering and bronzing on wood. Moscow. (in Russian) Yakovkin, I.F. (2008). Description of the Village of Tsarskoye or a Satellite viewing it. St Petersburg: Kolo Publishing House. (in Russian) 


\section{Appendix}

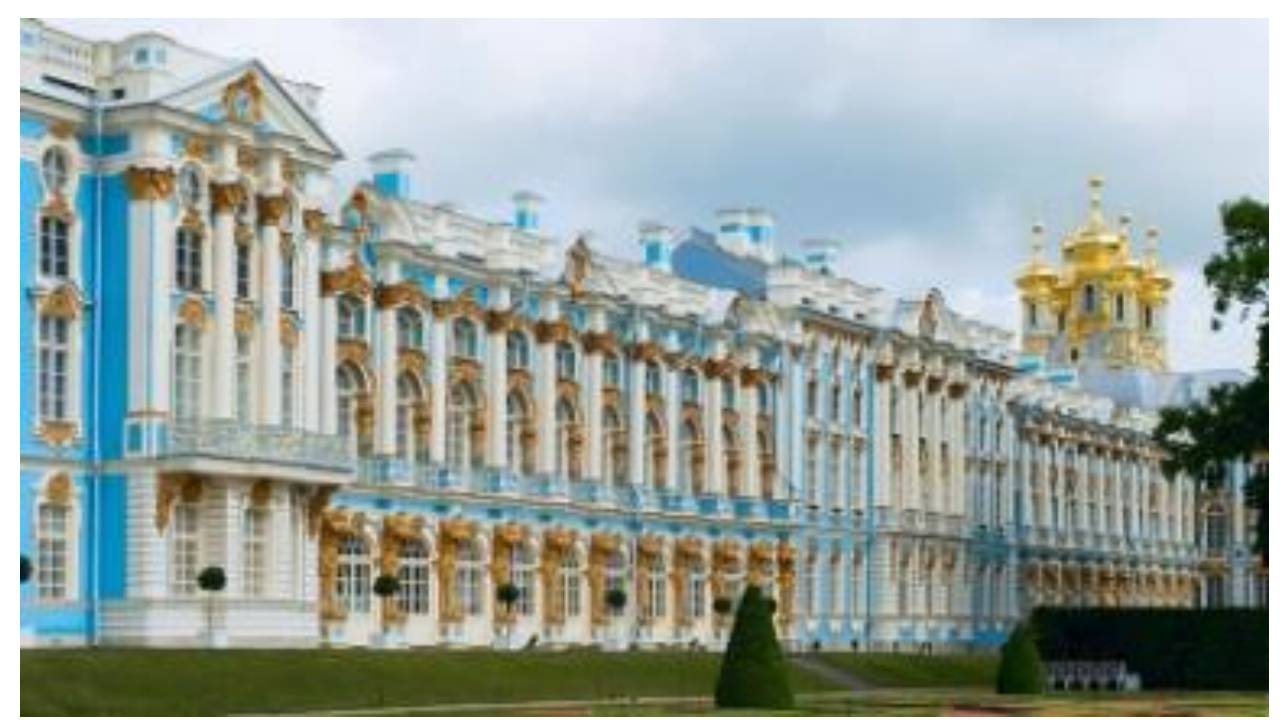

Figure 1. Catherine Palace of Tsarskoye Selo. Architect F. Rastrelli. Mid-18th century

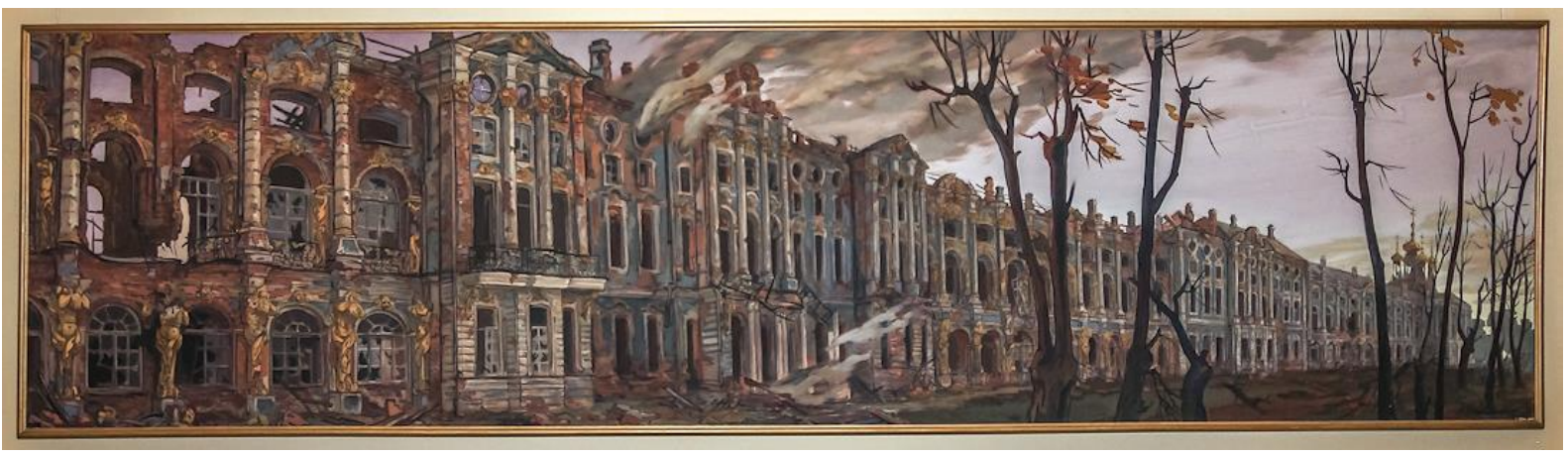

Figure 2. Panoramic picture. It shows the palace in a terrible state in 1944. The canvas reminds us how much damage the 1941-1945 war caused to the Catherine Palace of Tsarskoye Selo 


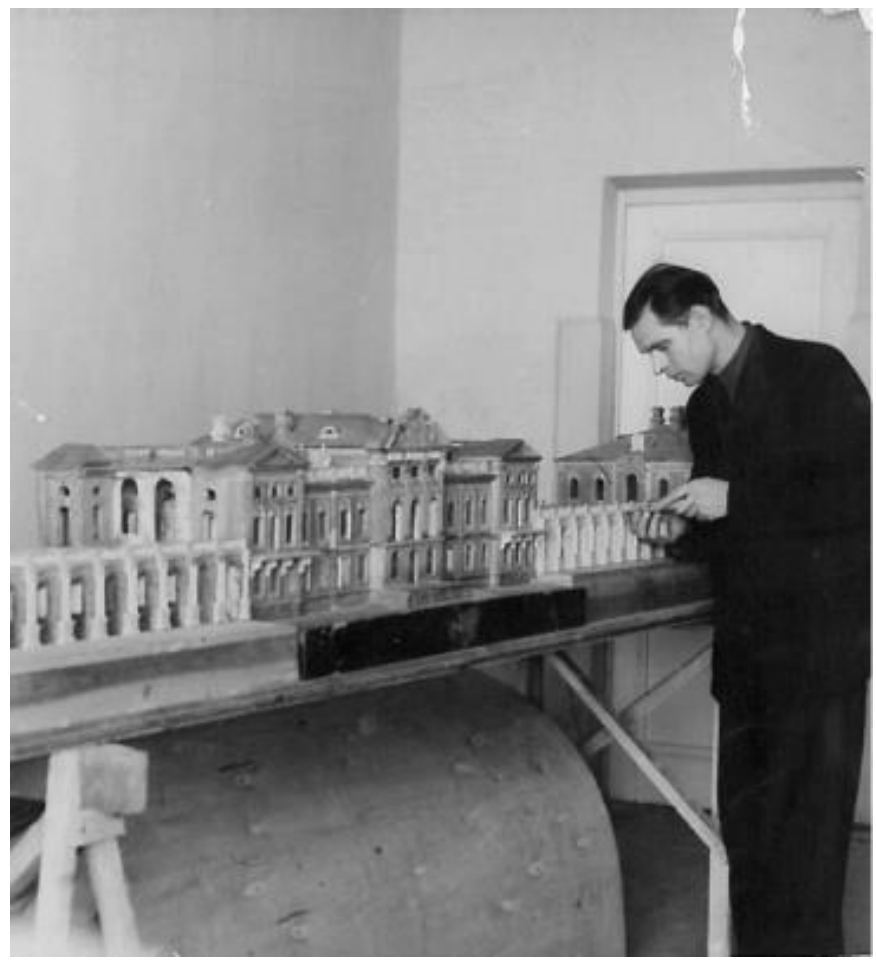

Figure 3. Restoration of the original historical model of the Catherine Palace of the 18th century by architect A.V. Kvasov by woodcarver Alexey Konstantinovich Kochuev (1930-40)

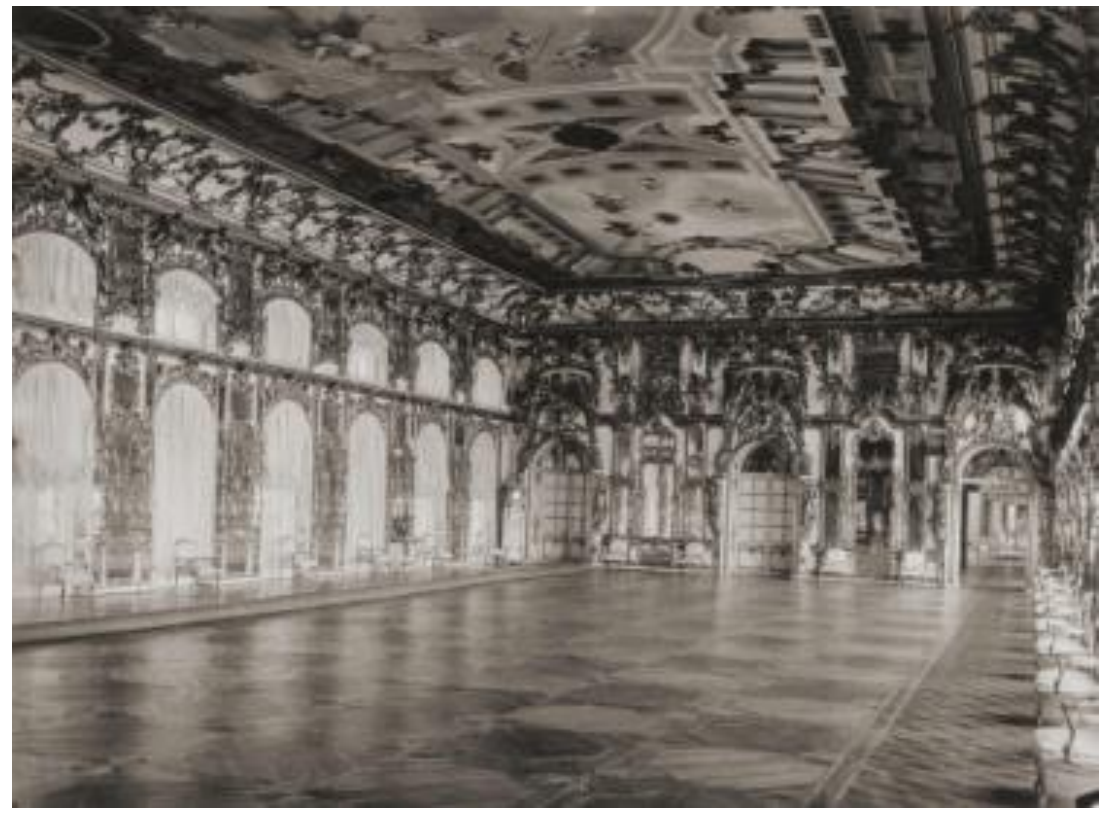

Figure 4. The Great Hall of the Catherine Palace before the revolution. 1912. 


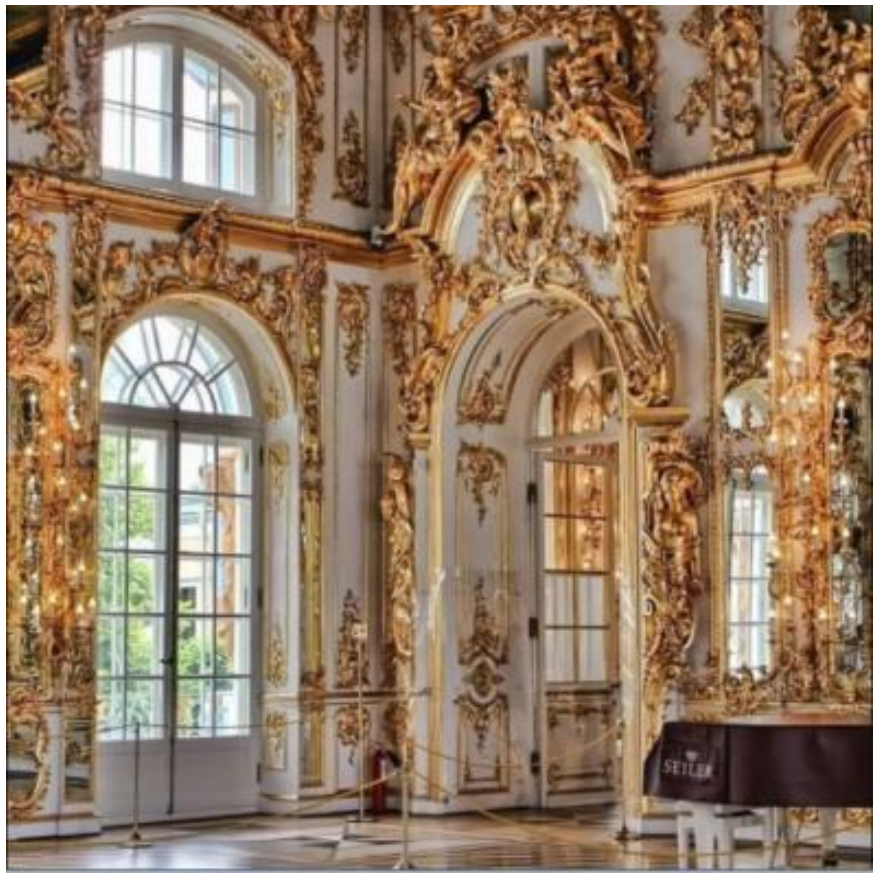

Figure 5. A fragment of the Great Hall. The south-eastern part. In the center of the photo, in the corner there is a panel with a detail designed to make baroque ornament replica

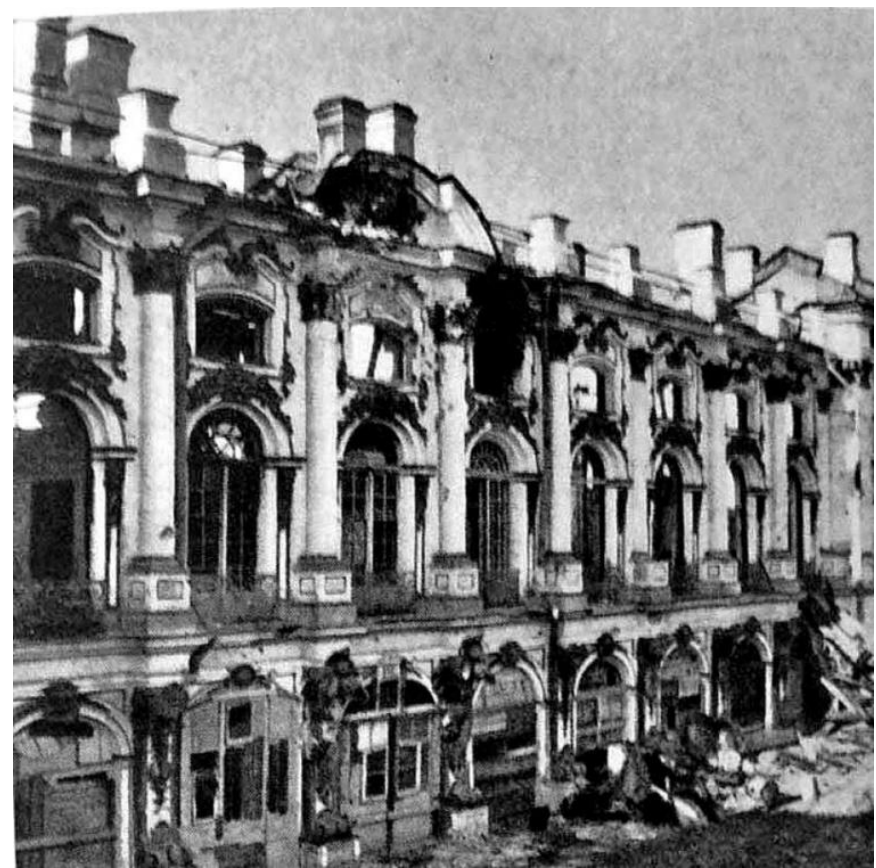

Figure 6. Catherine Palace after liberation in 1944. A fragment of the facade in the Great Hall area 


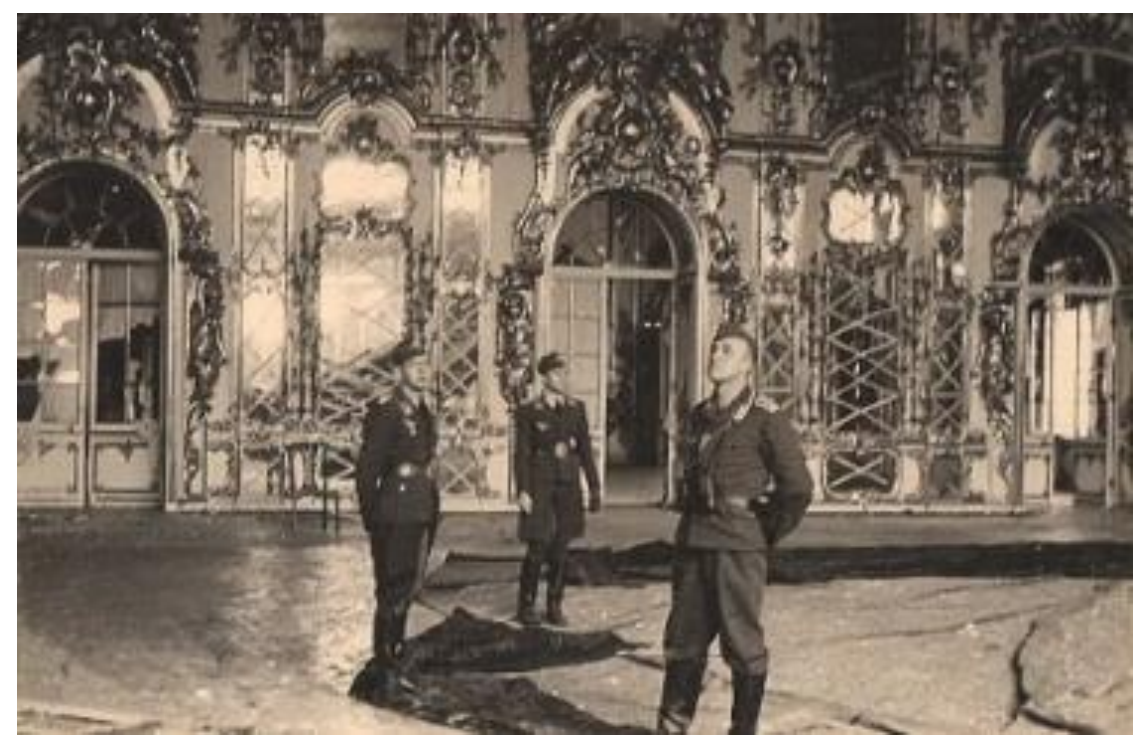

Figure 7. German soldiers in the Great Hall of the Catherine Palace during the occupation of the city of Pushkin (September 1941)

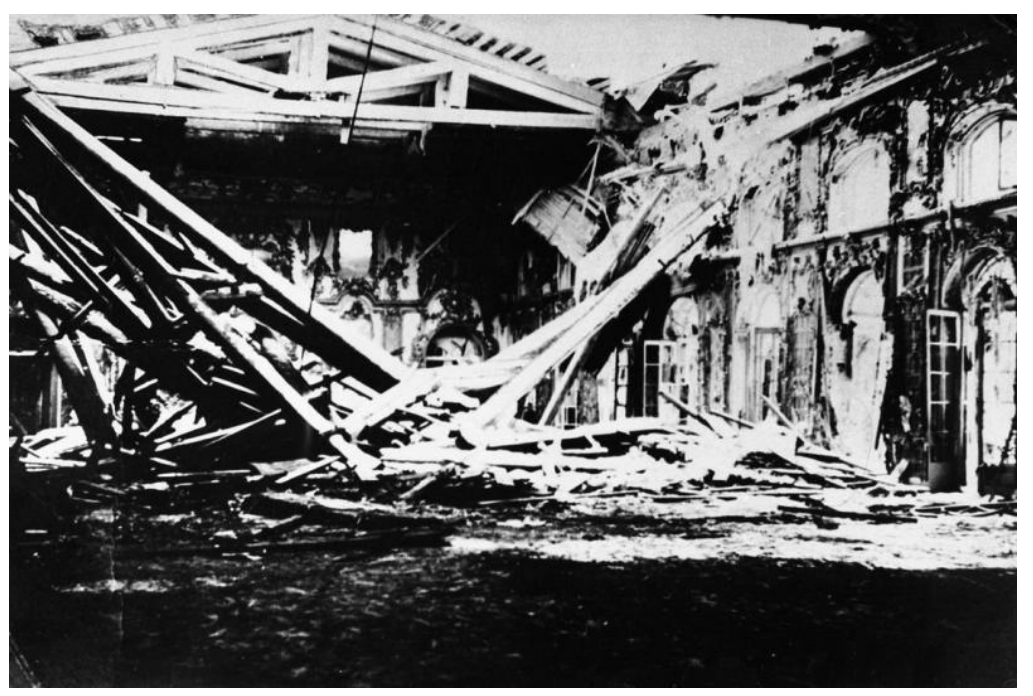

Figure 8. The Great Hall of the Catherine Palace in 1944 before restoration 


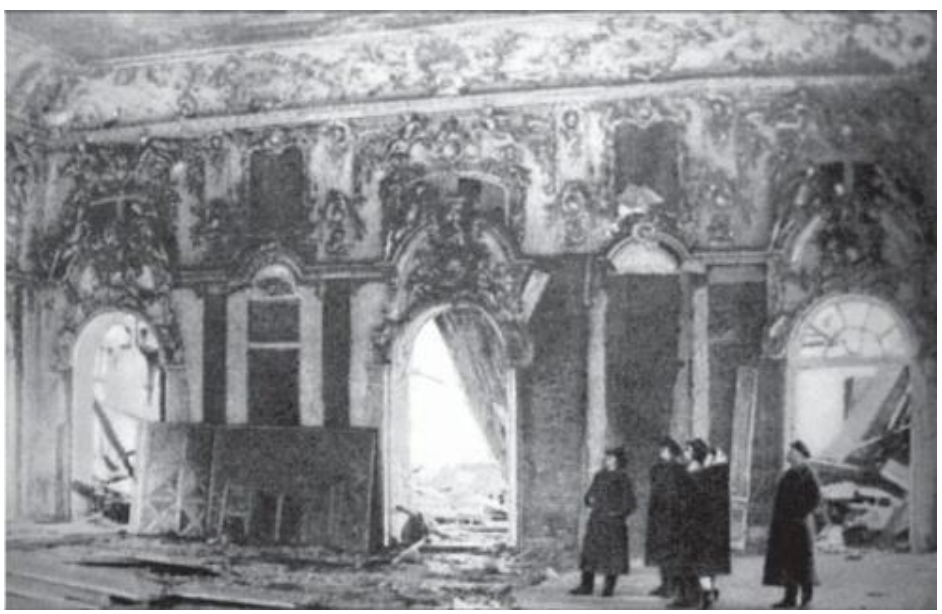

Figure 9. A commission of specialists examines the destruction of the Great Hall decor (1946). On the right is the Fomicheva's father Mikhail Grigorievich Voronov

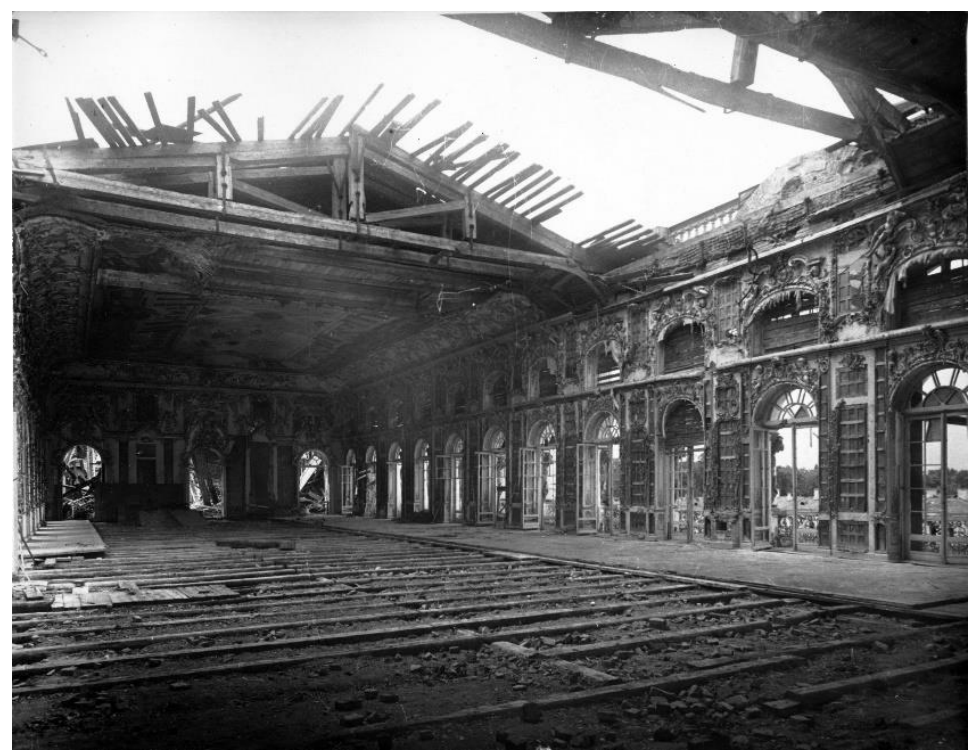

Figure 10. The Great Hall of the Catherine Palace in 1946 before restoration 


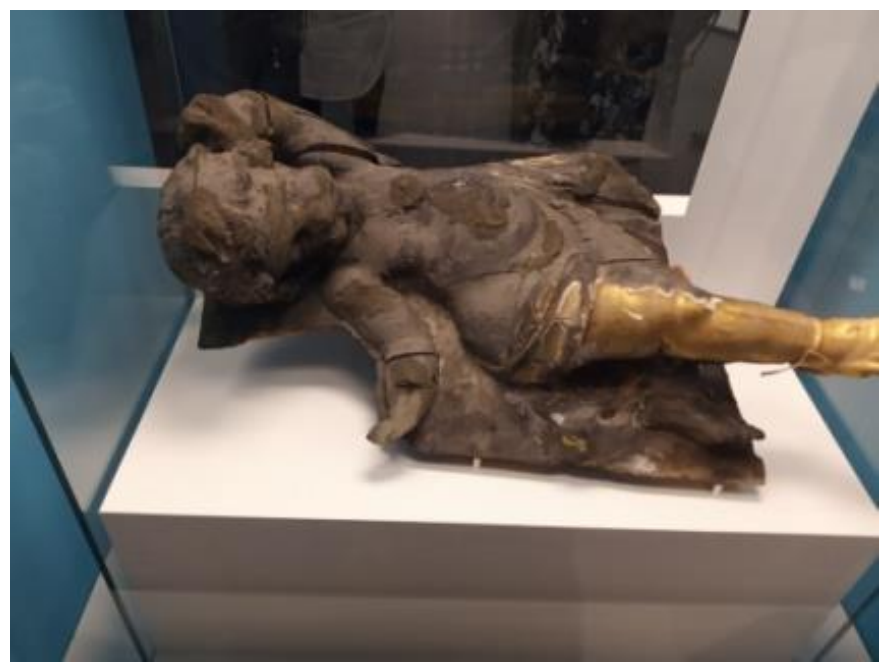

Figure 11. The ornamental path sculpture from the Great Hall composition, discovered in the rubble of the palace in 1944

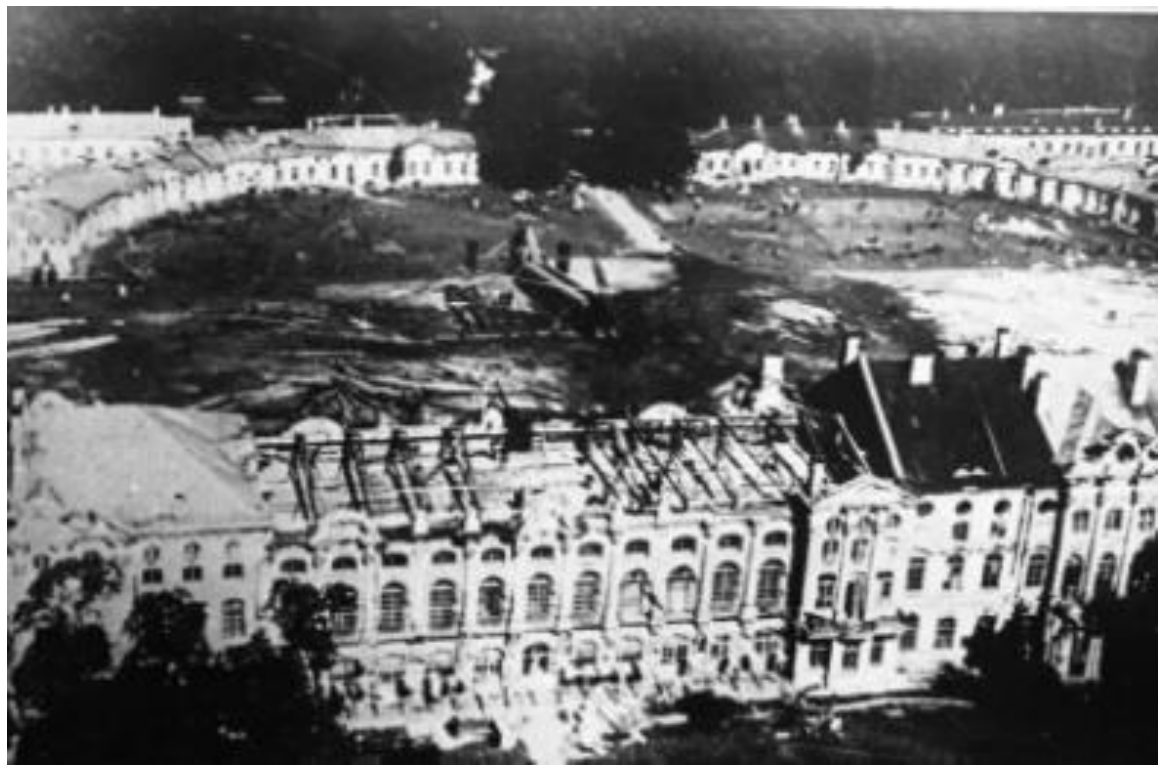

Figure 12. Catherine Palace. The Great Hall area during the trusses' replacement on June 17, 1959. View from the YAK-24 helicopter 


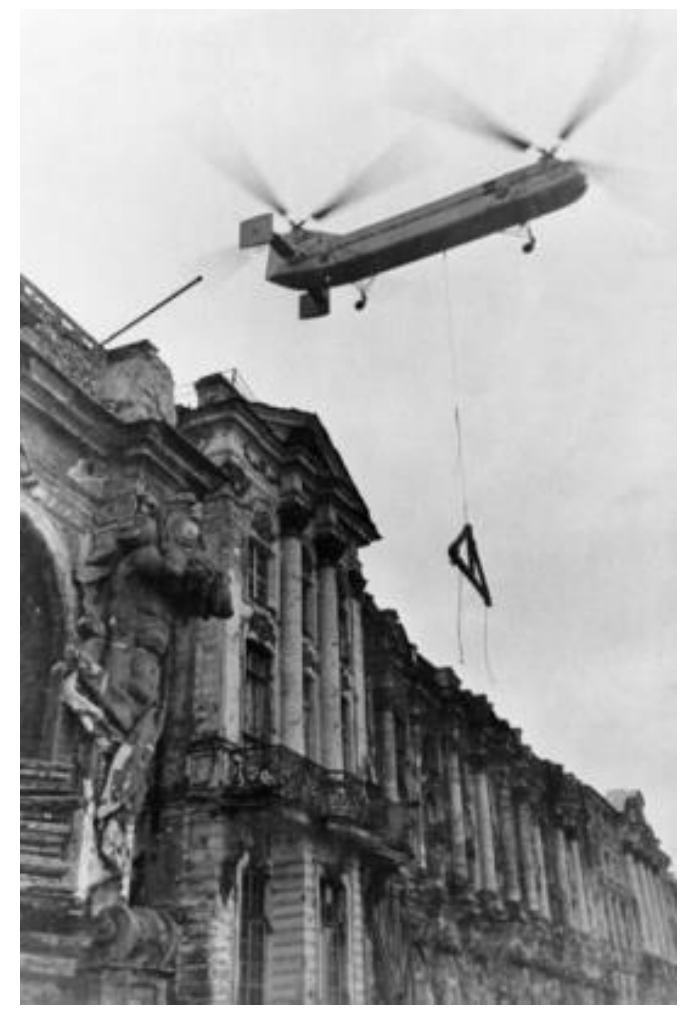

Figure 13. Installation of new trusses over the Great Hall on June 17, 1959. Helicopter commander I.S. Grigoriev

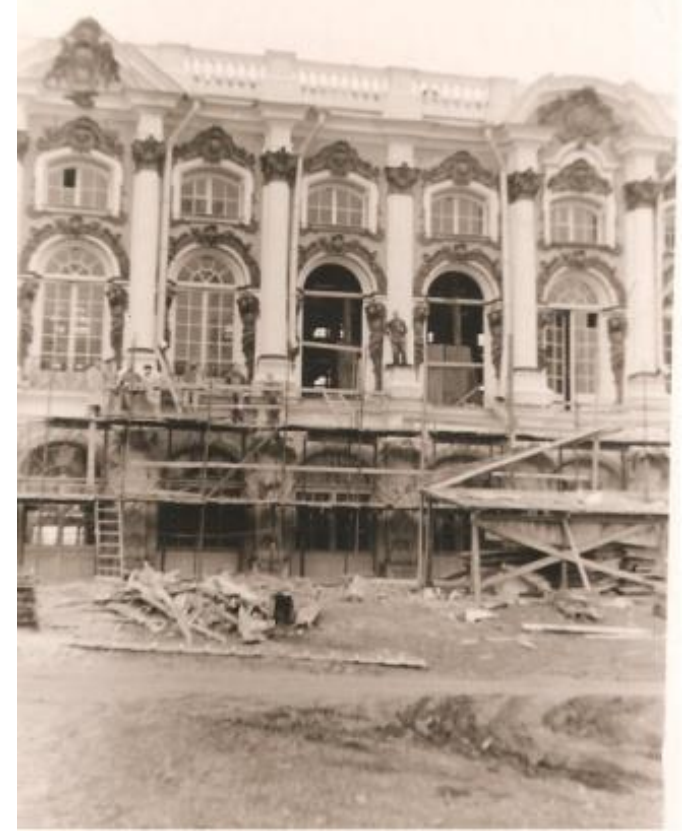

Figure 14. Restoration of the Catherine Palace facades in the Great Hall area. (1960 years) 


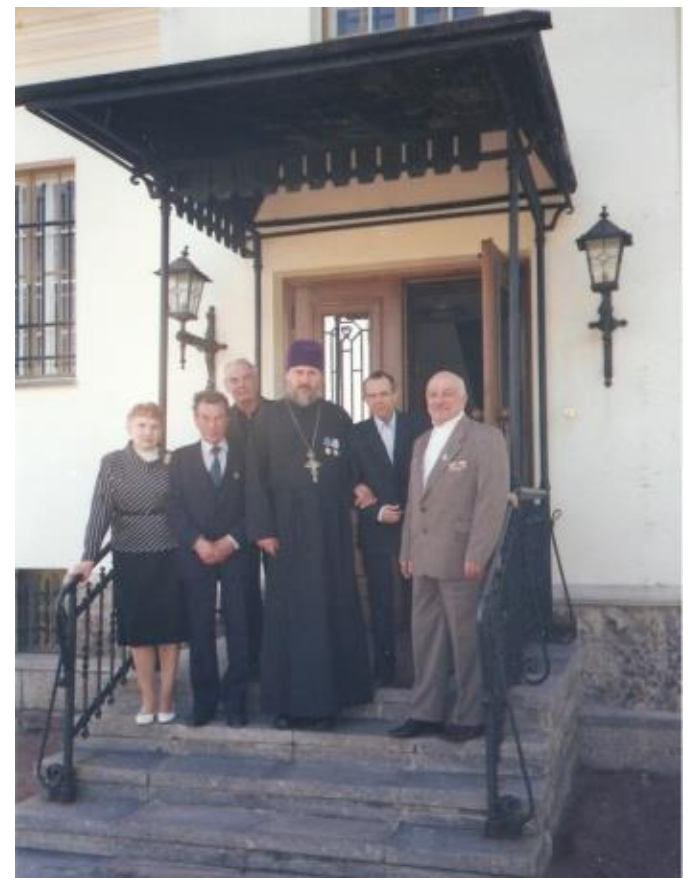

Figure 15. Plasterers of the brigade of Vasiliev Anatoly Ivanovich (second from left), followed by Nikolaev Ivan Nikolaevich, far right - Nikolai Alekseevich Chervyakov (far right) on the porch next to the dean of the Tsarskoye Selo district, Father Gennady Zverev

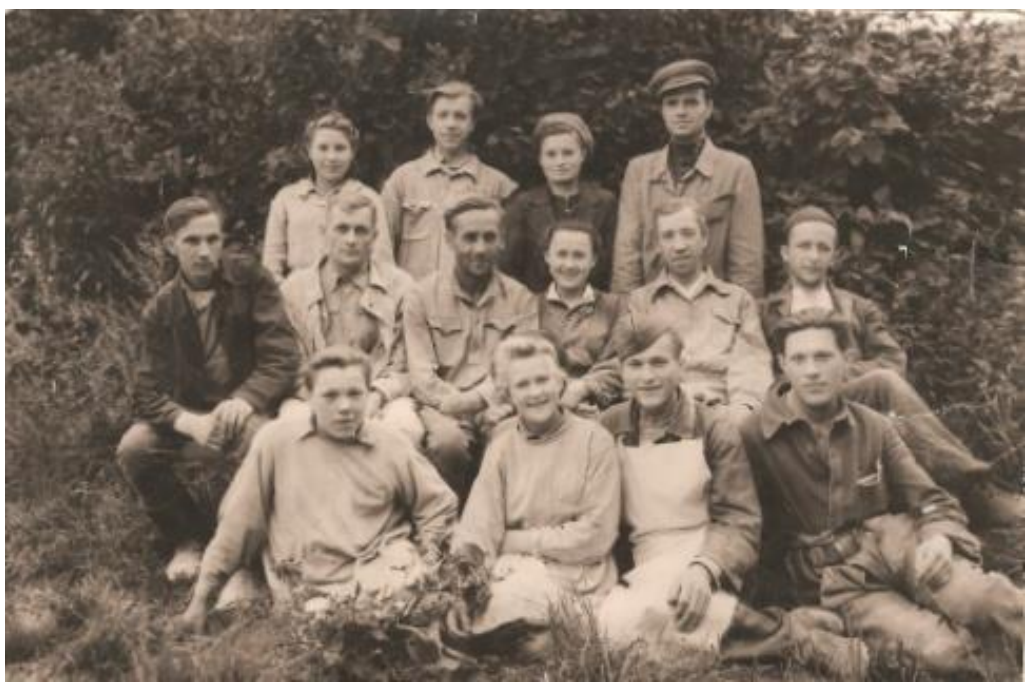

Figure 16. The first team of sculptors. July 1946 Valentin Chervyakov, Lidiya Ovsyannikova, Vera Vasilyevna Zaitseva (in the center of the middle row) 


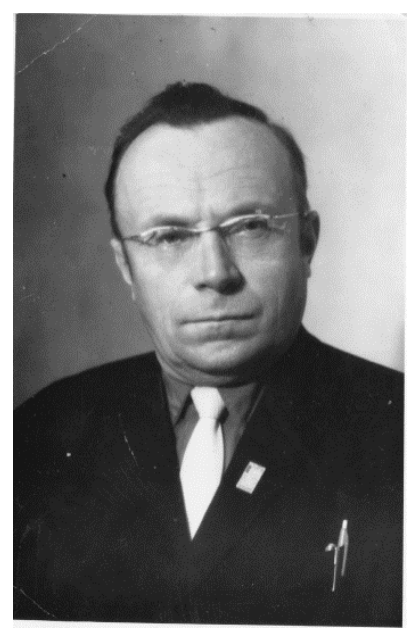

Figure 17. Anatoly Mikhailovich Kuchumov. Director of the Central Repository of Museum Funds of Suburban

Palaces. Chief Curator of the Pavlovsk Palace

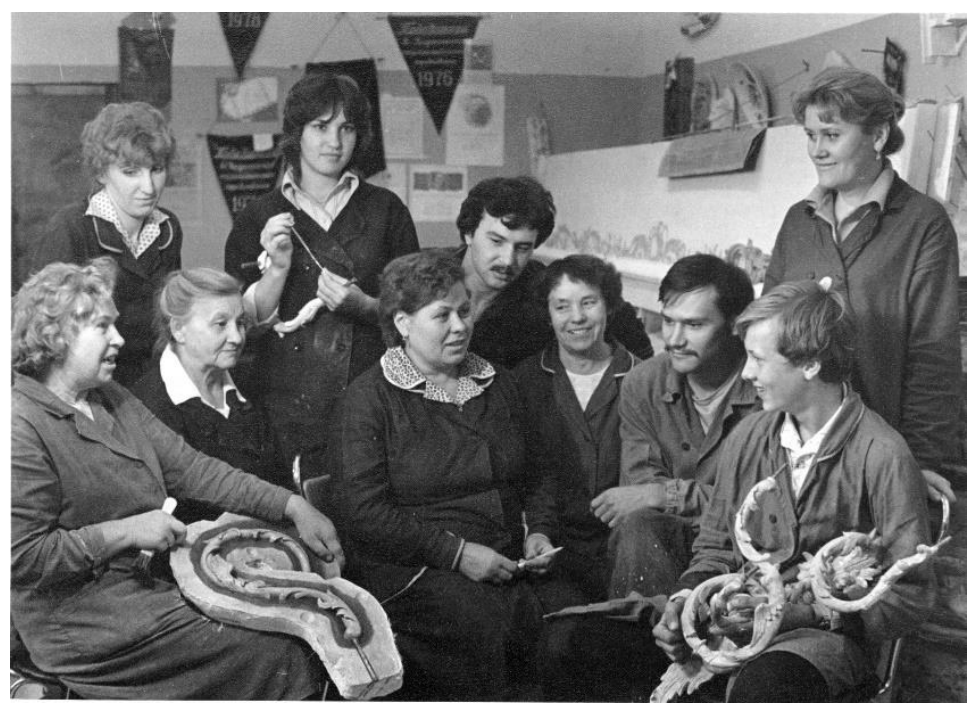

Figure 18. A team of modelers with models of girandoles (from left to right) 1st row: N.A. Cupidonova, O.V.

Bychkova, F.A. Lebedeva, E.N. Anokhina, K. Semenov, Y. Cherednikov; 2nd row: N. Polyakova, N.P. Burlova 


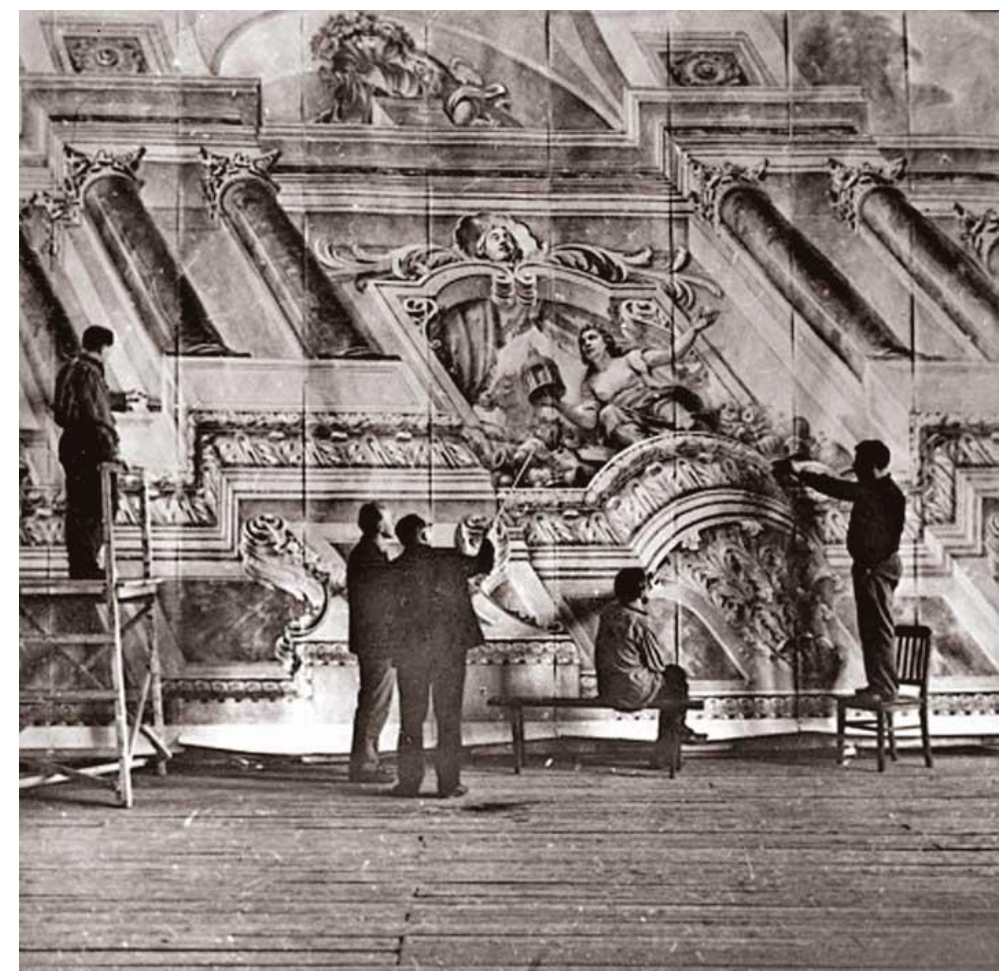

Figure 19. The foreman of the painters Y.A. Kazakov discusses the sketch details of the architectural detail of the Great Hall ceiling with the chief architect of the palace restoration project A.A. Kedrinsky (in the center), on the shelf on the left is V.G. Zhuravlev

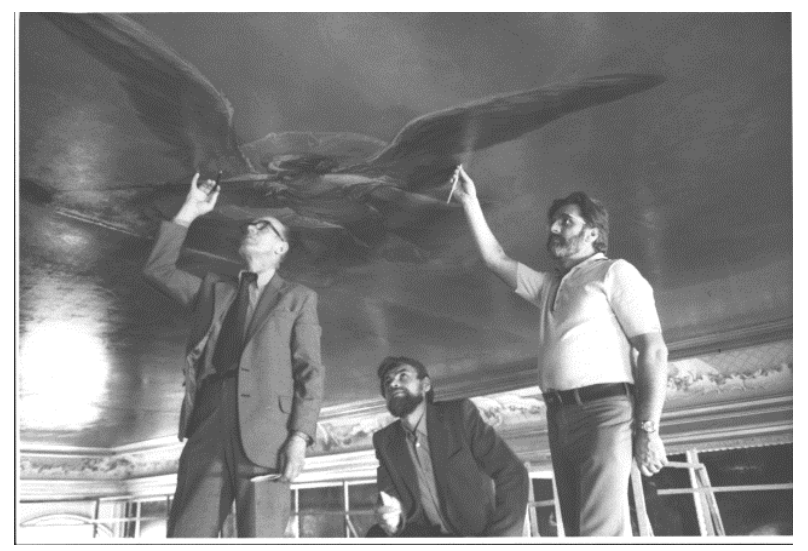

Figure 20. Painters of the Y.A. Kazakov brigade B. Golovanov (in the background) and B.N. Lebedev (next to Kazakov) for the execution of the architectural part of the ceiling lamp on the ceiling of the second Anticamera 


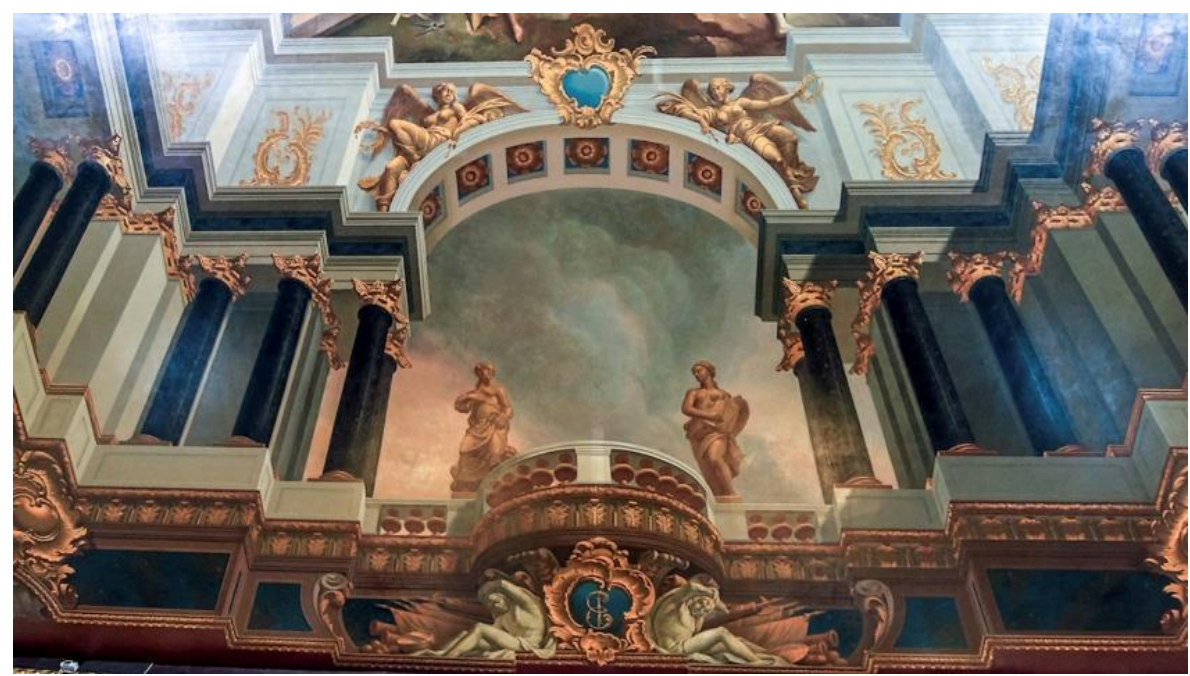

Figure 21. A fragment of the architectural detail of the Great Hall ceiling in colour

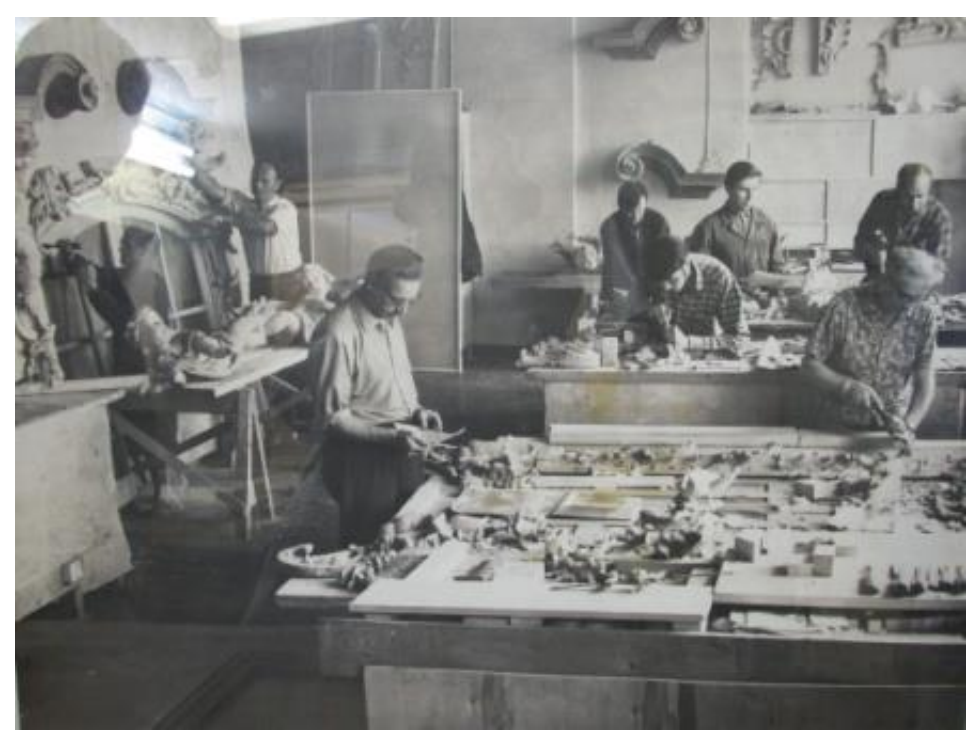

Figure 22. A.K. Kochuev's team of carvers at work on recreating the carved sculptural and ornamental decor of the Great Hall in the room of the second Anti-Chamber in 1970. In the foreground: A.K. Kochuev and A.V. Vinogradov, between them A.S. Antonov, D.P. Andreev, O.F. Timofeev, and V.A. Bogdanov at the wall. At the composition on the left: M. Mukhin and Y.M. Kozlov 


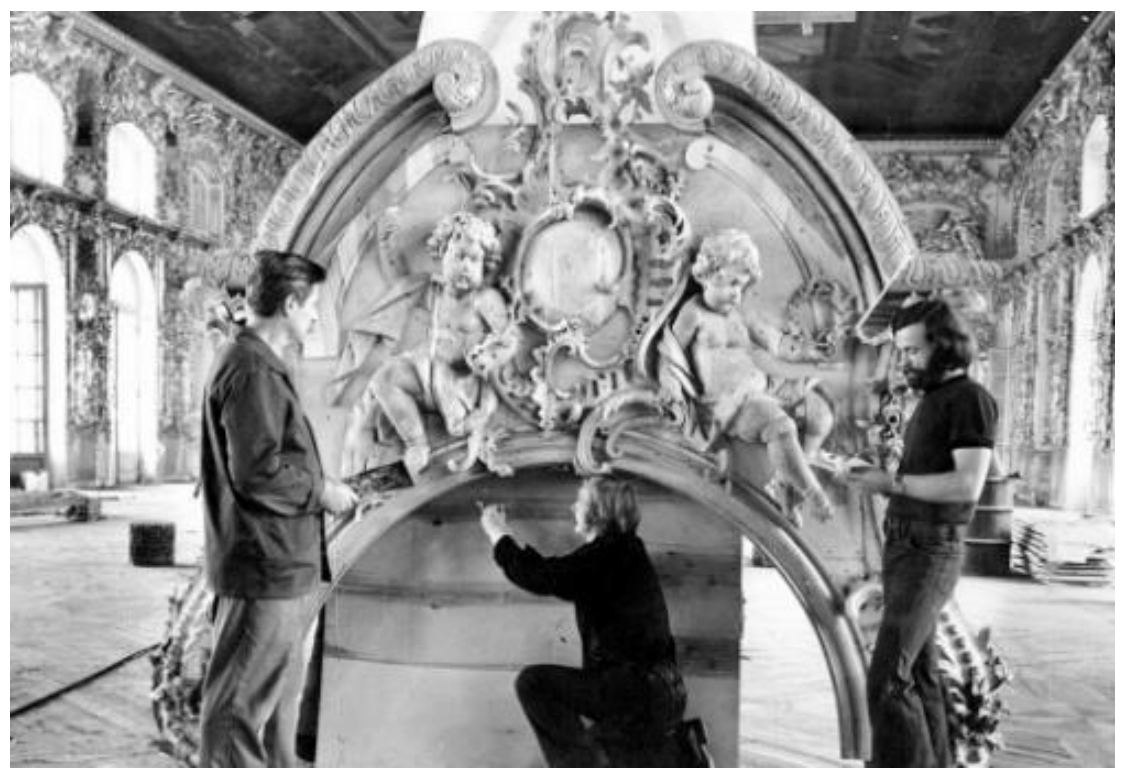

Figure 23. The doorway of the southern wall of the Great Hall after the restoration of the carving before installation on a historical site.

Wood carvers: Oleg Fedorovich Timofeev, Alexander Alexandrovich Kedrinsky (youngest son), Vladimir Konstantinovich Chekushin

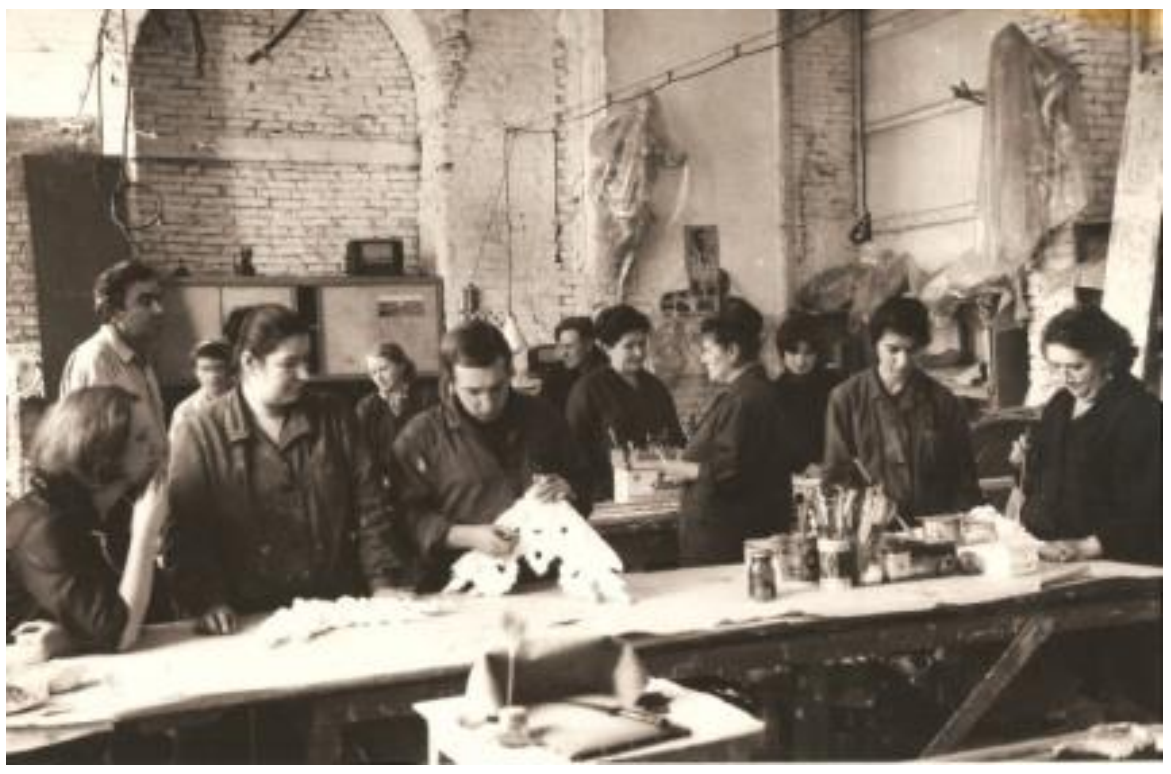

Figure 24. The brigade of K.D. Maurichev's gilders in the room of the third Anti-camera. 1969 


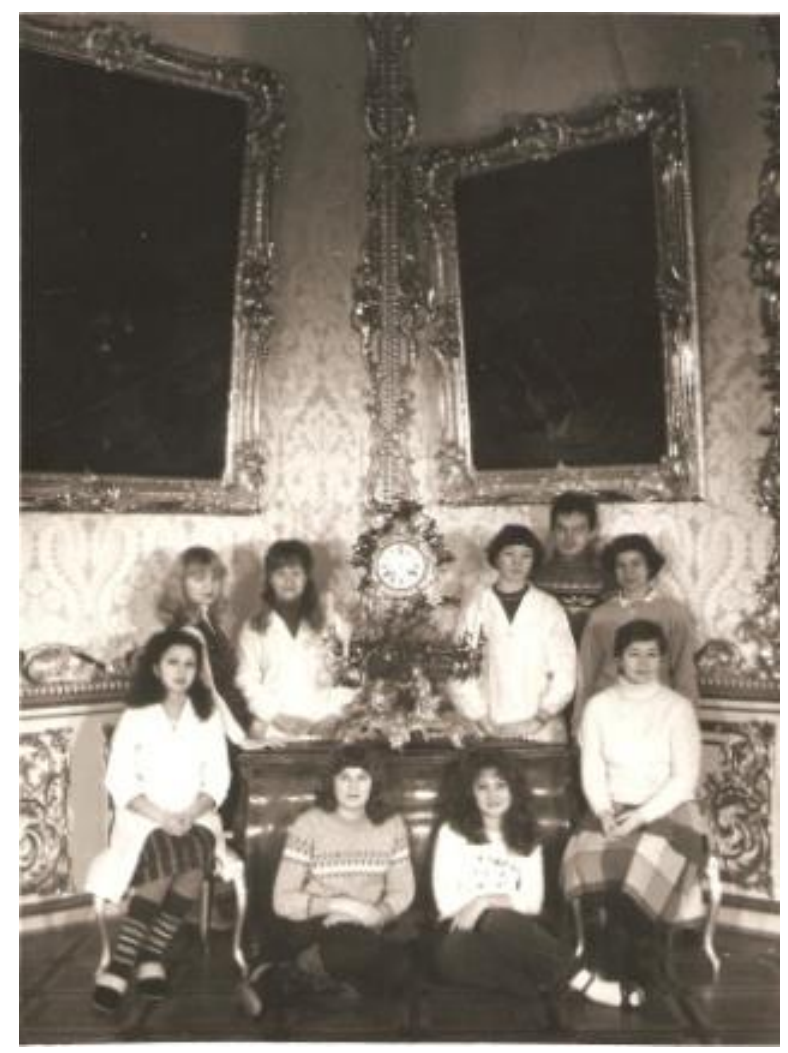

Figure 25. Catherine Palace. White formal dining room. 1985. The gilders of the Fomicheva brigade (from left to right) 1st row: M. Morozova, G. Efremova, M. Zavgorodnaya, N. Ovchinnikova; second row: L. Petrova, G. Korneva, T. Akimova, P. May, N.

Fomicheva
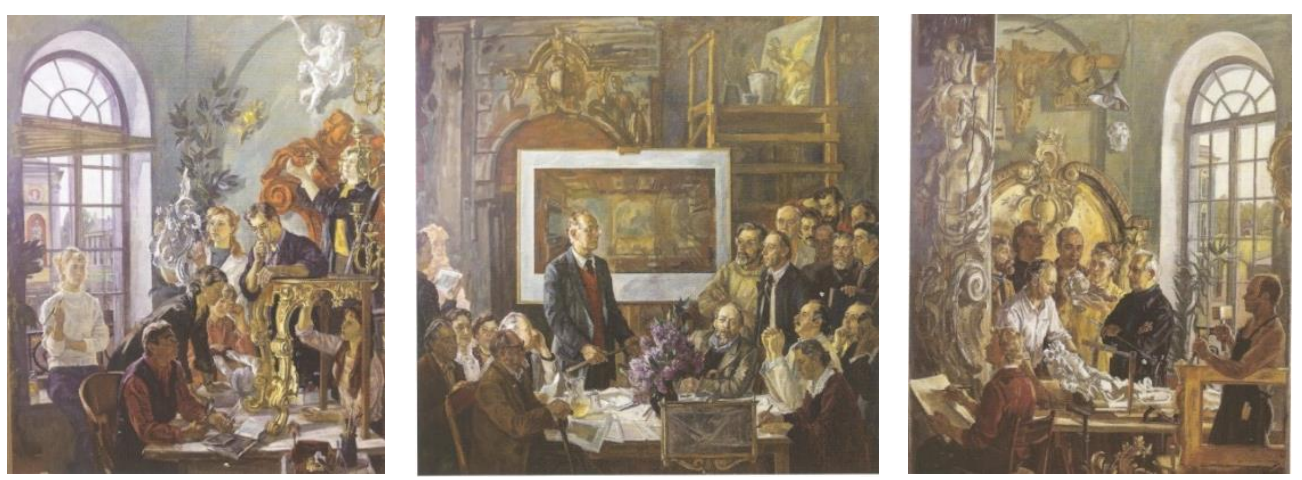

Figure 26-28. Triptych "Restorers". Artist V.A. Lednev.1985. Gilders. Painters. Wood Carvers 

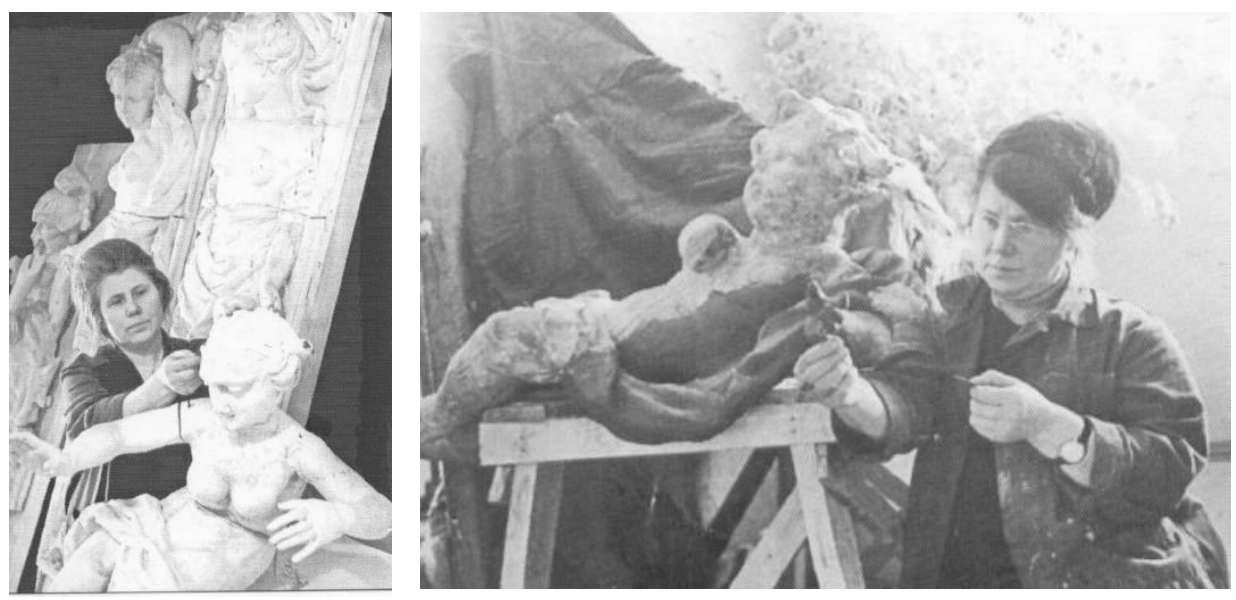

Figure 29-30. Lilia Mikhailovna Shvetskaya at work
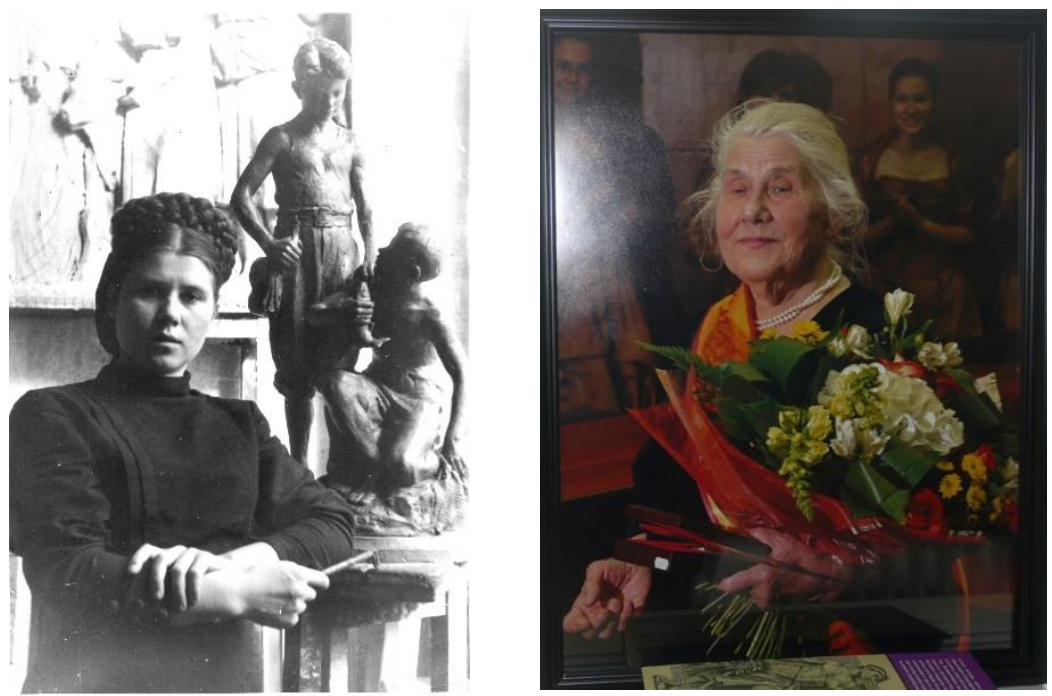

Figure 31. Lilia Mikhailovna Shvetskaya is a student of the V.I. Mukhina College

Figure 32. Sculptor Lilia Mikhailovna Shvetskaya, honorary citizen of Tsarskoye Selo 


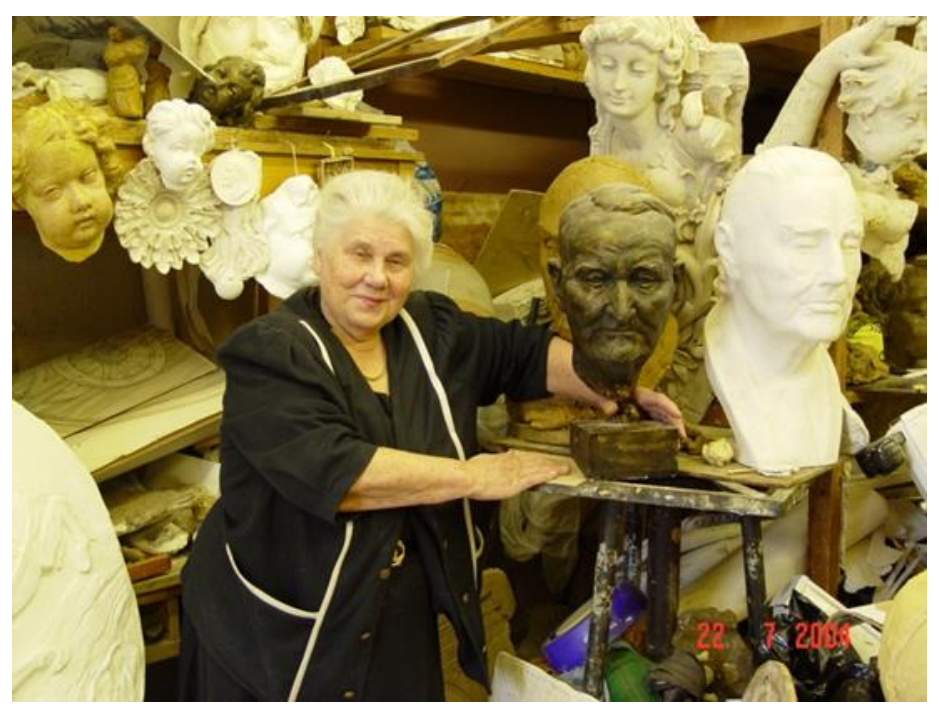

Figure 33. Lilia Mikhailovna Shvetskaya in the workshop
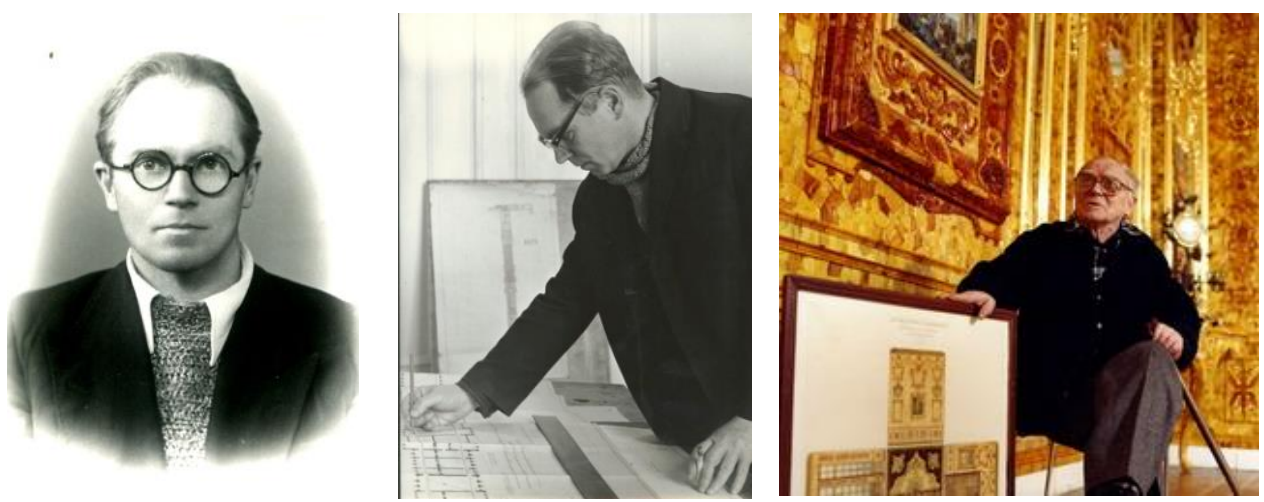

Figure 34-36. Alexander Alexandrovich Kedrinsky, the chief architect of the Catherine Palace restoration project, three times winner of the State Prizes of Russia, the first Honorary citizen of Tsarskoye Selo 


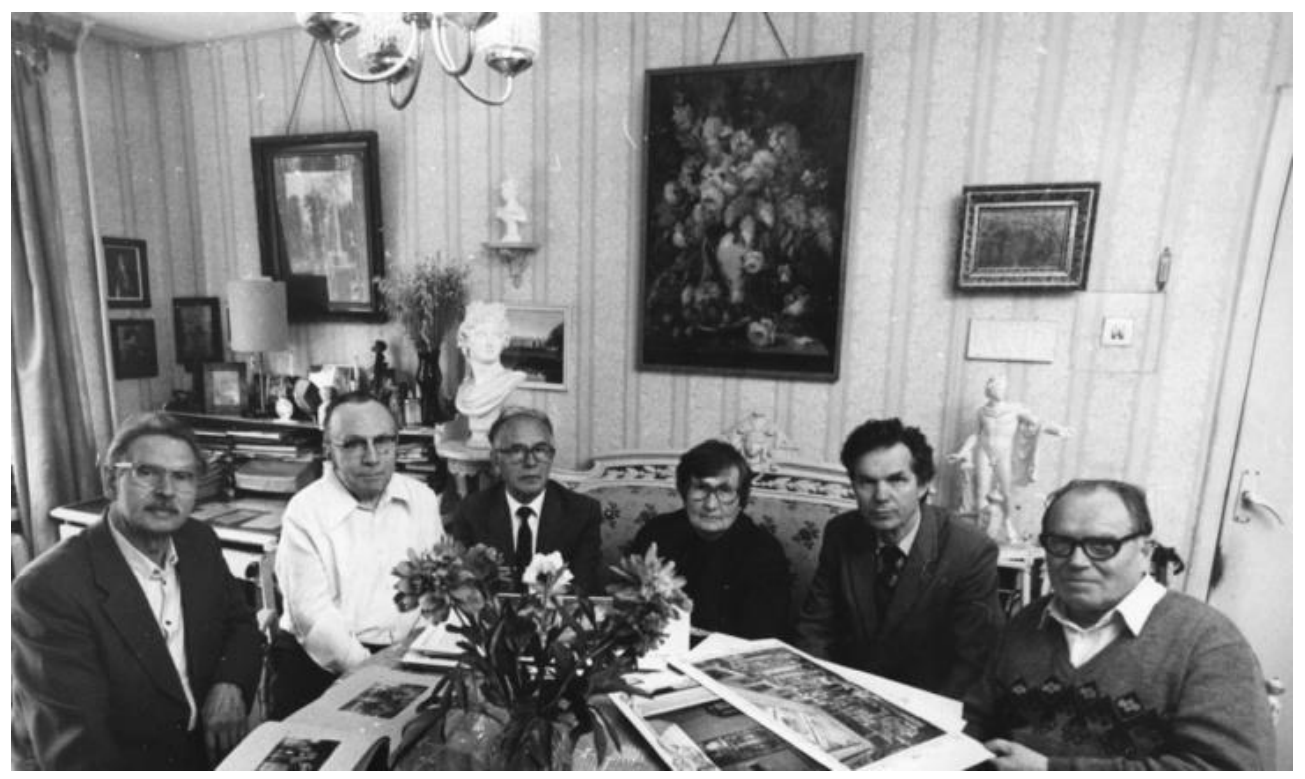

Figure 37. Winners of the Lenin Prize in 1986: A.K. Kochuev, A.M. Kuchumov, Ya.A. Kazakov, N.I. Ode, P.P. Ushakov, A.A. Kedrinsky

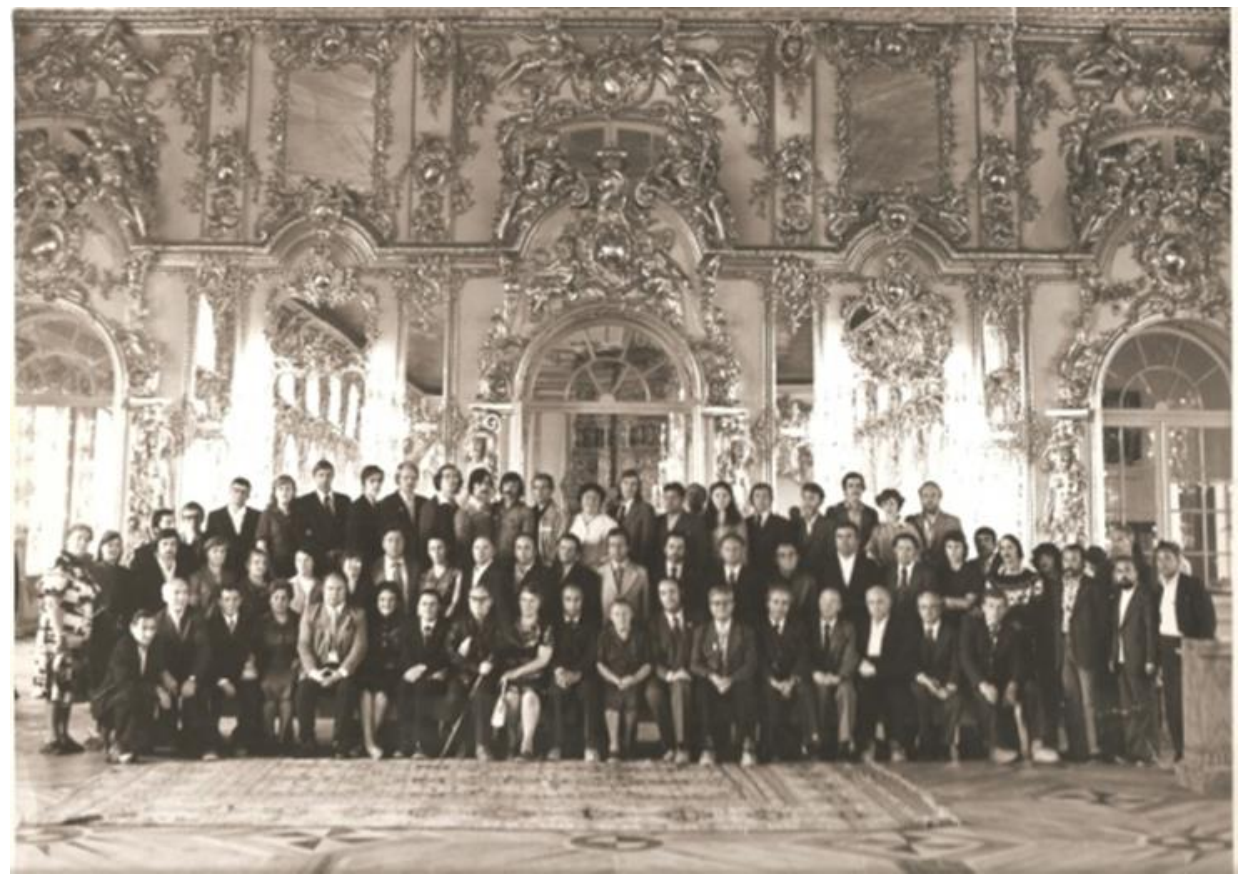

Figure 38. July 10, 1980. The opening day of the Great Hall after the restoration. A restorers' team and museum staff against the background of the northern wall of the hall 


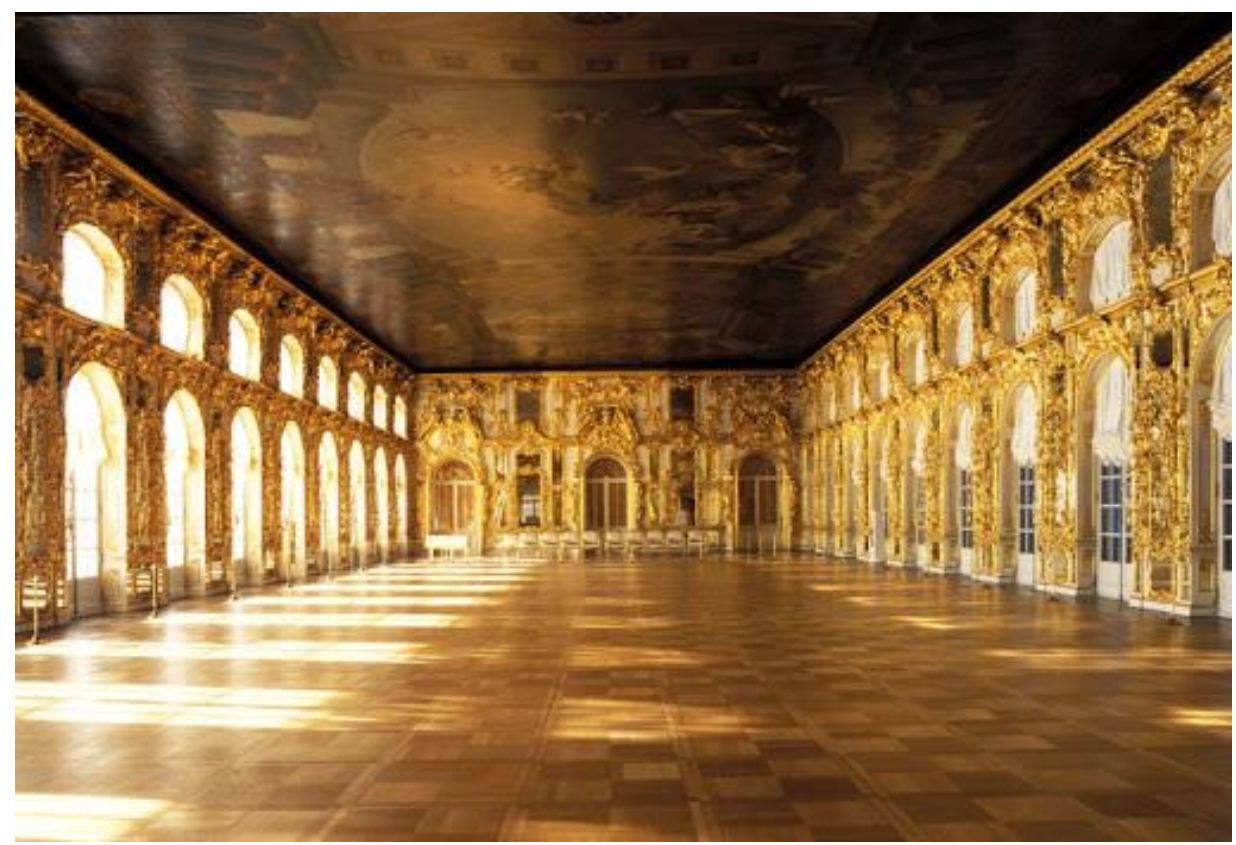

Figure 39. General view of the Great Hall of the Catherine Palace after restoration. 1969-1985

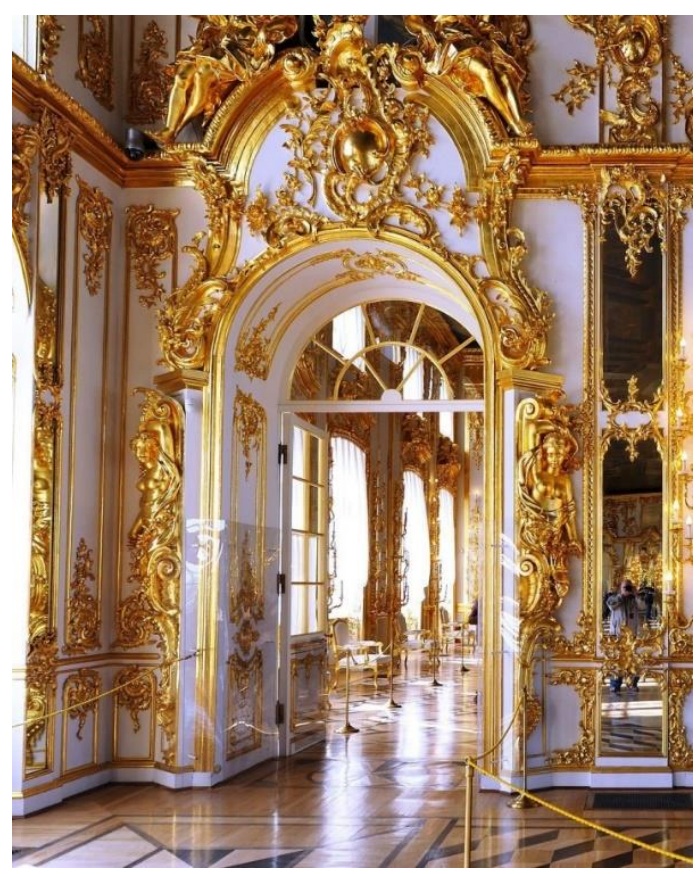

Figure 40. A fragment of the Great Hall and its gilded carved decor during the transition to the 1 st Anti-Chamber. To the left of the caryatid on the vertical panel are analog ornaments for making a replica of the Baroque decor. 

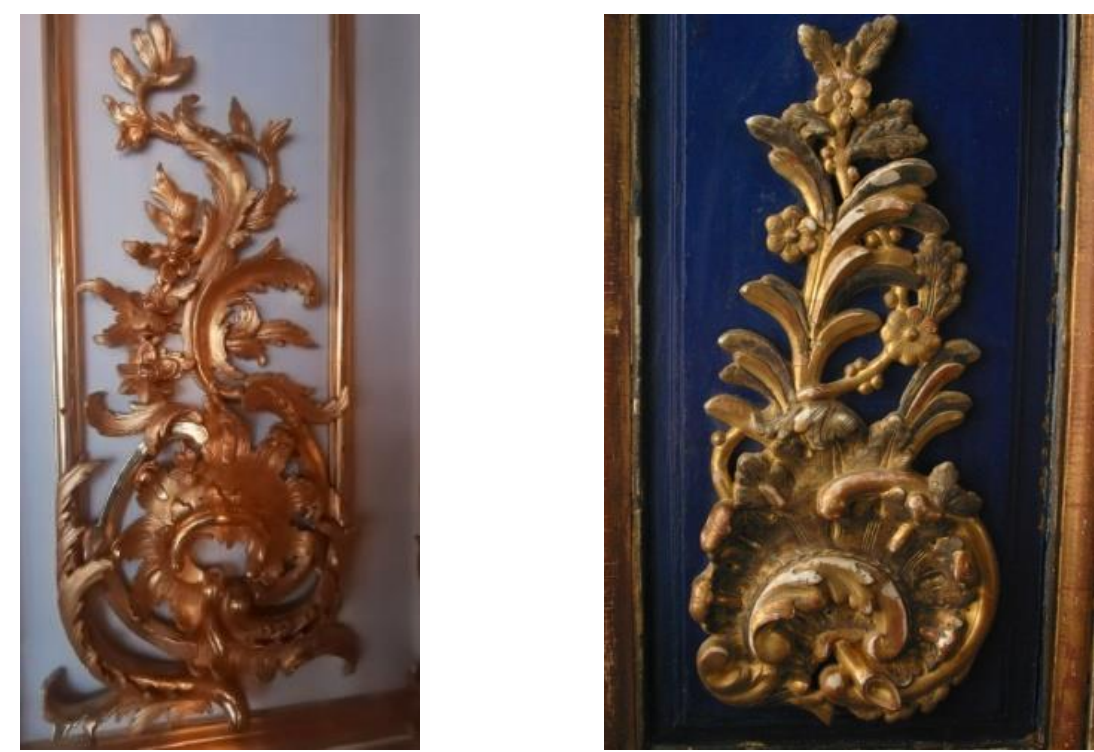

Figure 41. Ornamental gilded wood carving. The Great Hall of the Catherine Palace. 1748-1752. (Architect F. Rastrelli)

Figure 42. Gilded papier-mache molding from the house church of the Catherine Palace. 1820. (Architect V.P. Stasov based on wood carving F. Rastrelli)
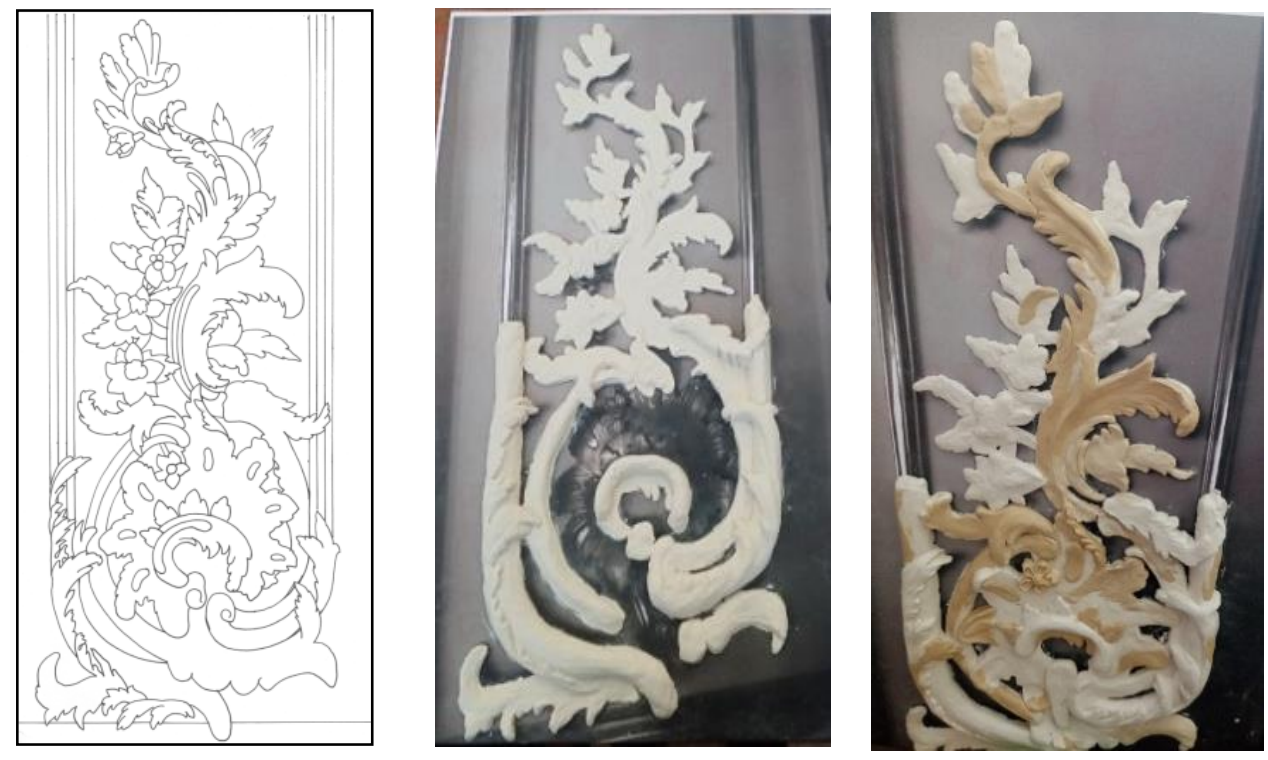

Figure 43-45. Graphic image of the drawing. Laying with plasticine according to the drawing. Creating a three-dimensional ornament in plasticine 

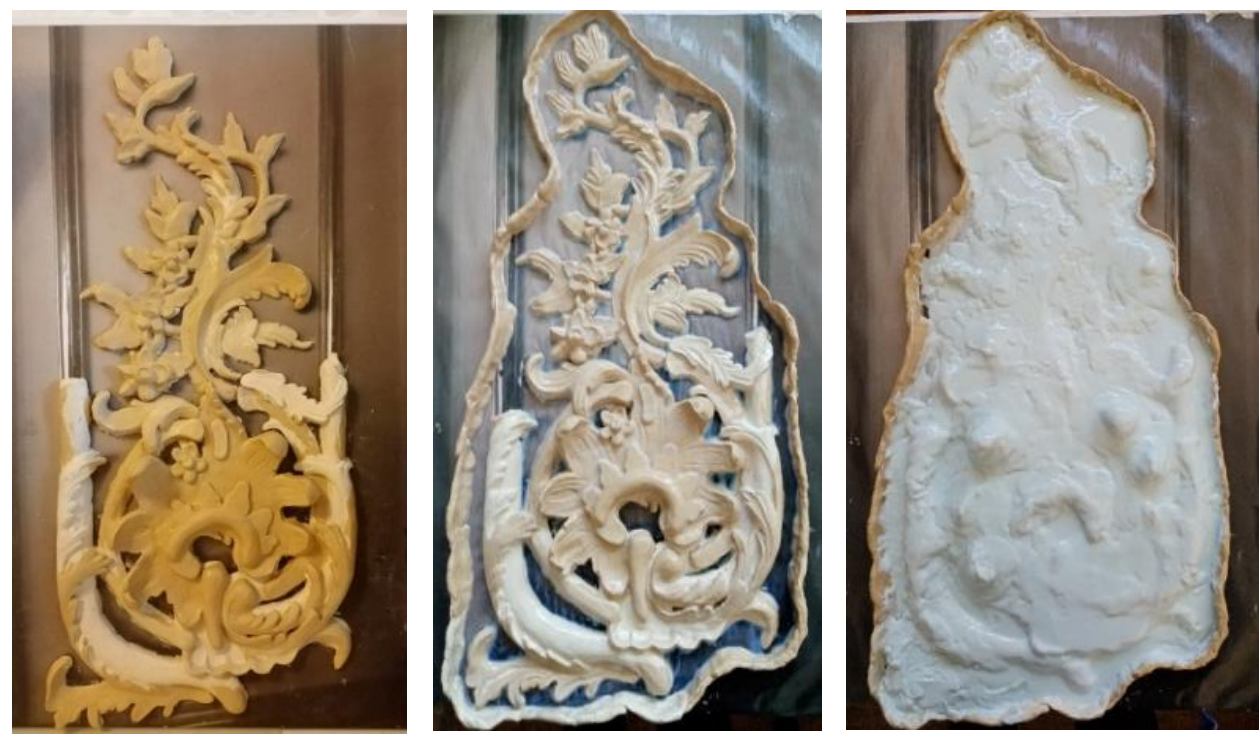

Figure 46. Modified in plasticine model

Figure 47. The model is varnished with executed fences

Figure 48. Forming the model
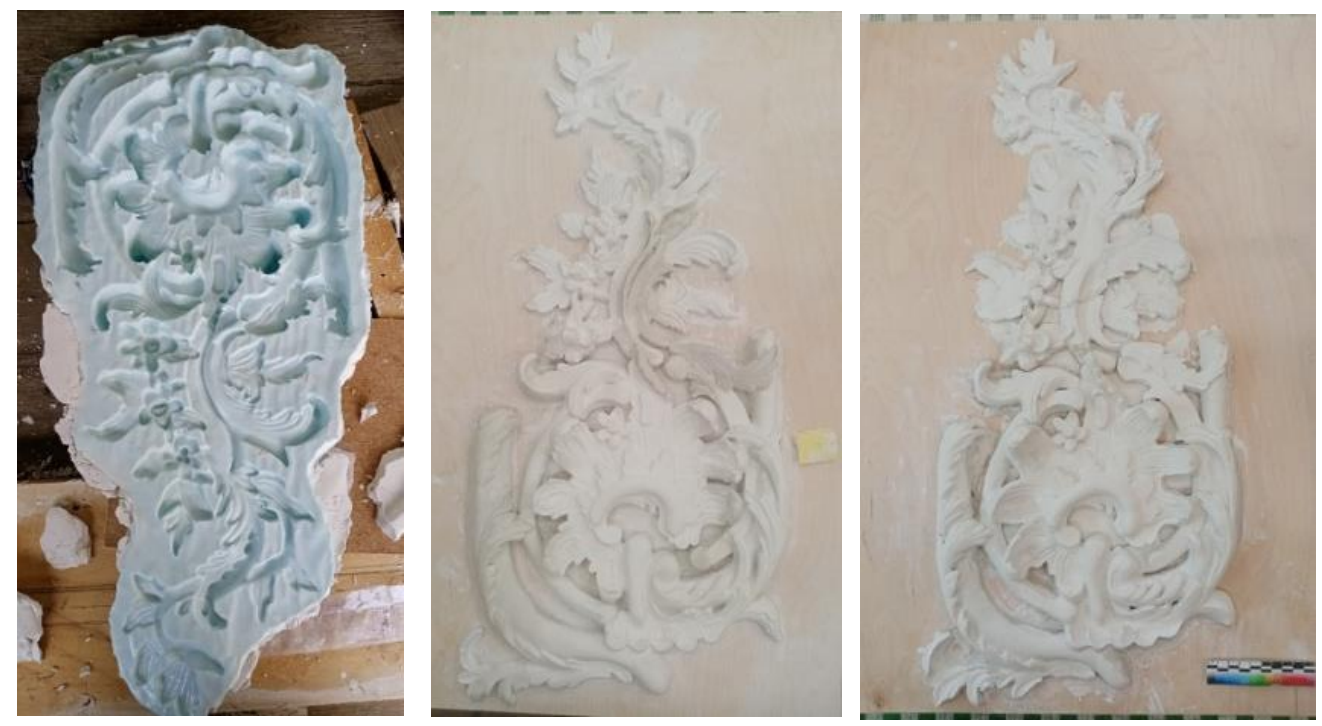

Figure 49. Silicone mold

Figure 50. Finishing gypsum casting

Figure 51. Modified gypsum casting 


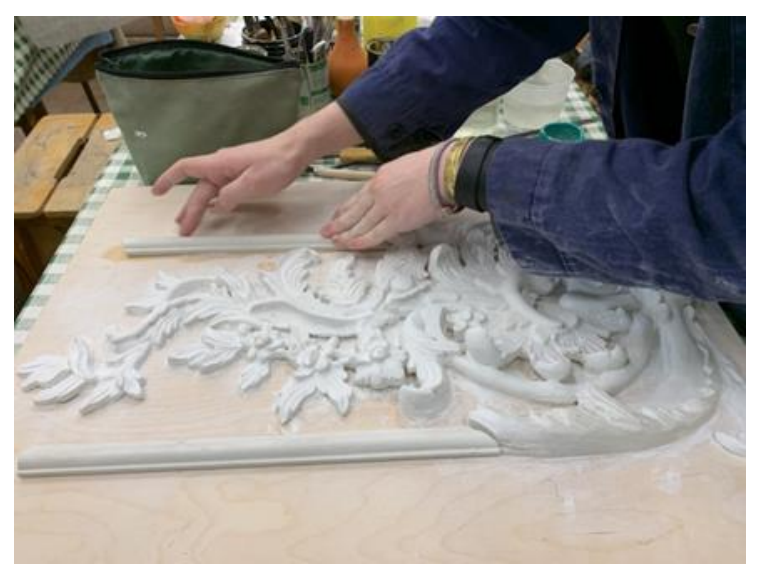

Figure 52. Selection of profile traction for the ornament
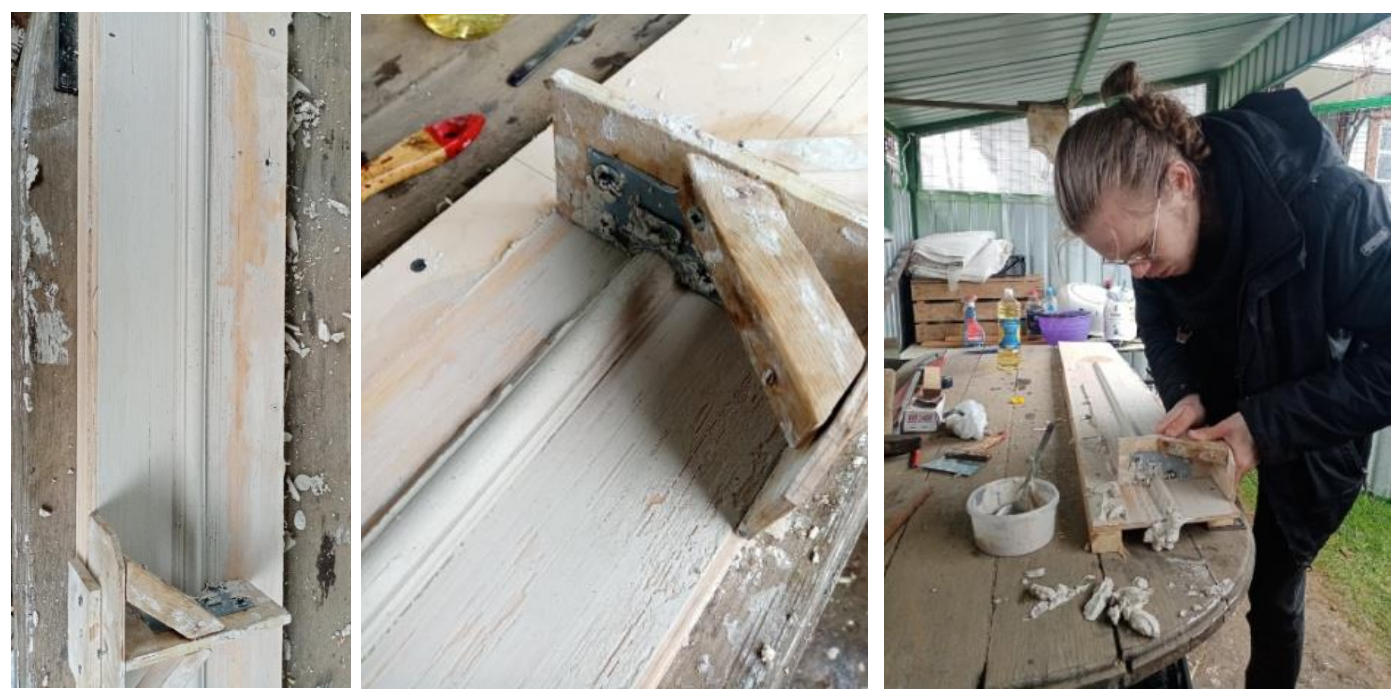

Figure 53. Manufacture of traction

Figure 54. Manufacture of traction with a profile

Figure 55. The process of manufacturing traction with a profile 

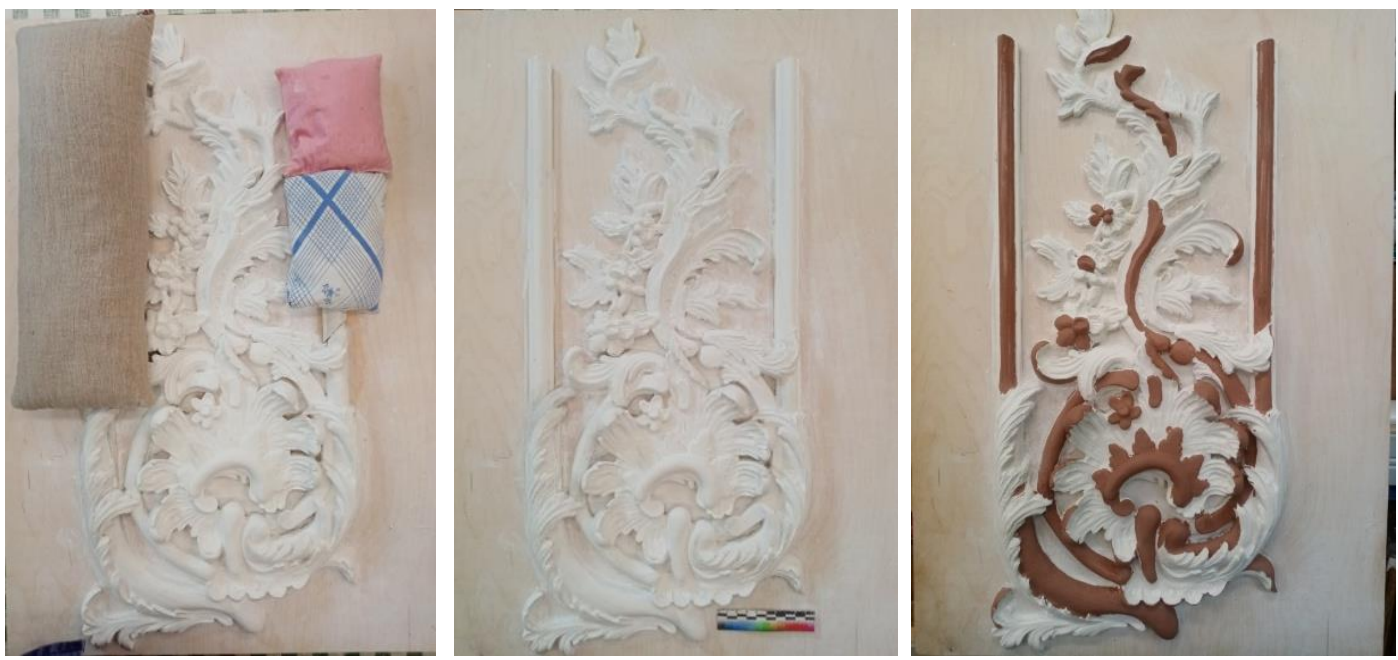

Figure 56. Installation of rods on a tablet under load

Figure 57. A finishing part ready for finishing in the form of imitation gilding Figure 58. The beginning of finishing the part is the allocation of places of imitation gilding on the poliment
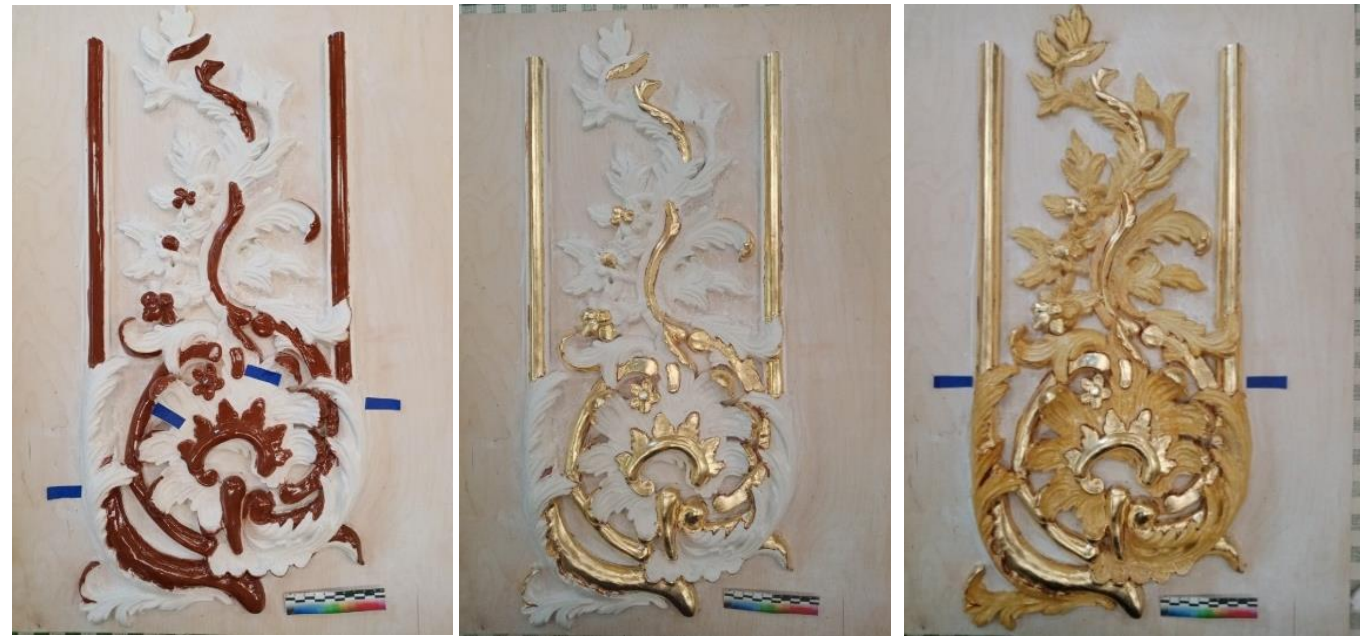

Figure 59. Application of oil varnish before imitation of glossy gilding with pot.

Figure 60. Imitation of glossy gilding with pot

Figure 61. Covering the ornament with shellac alcohol and oil lacquers 

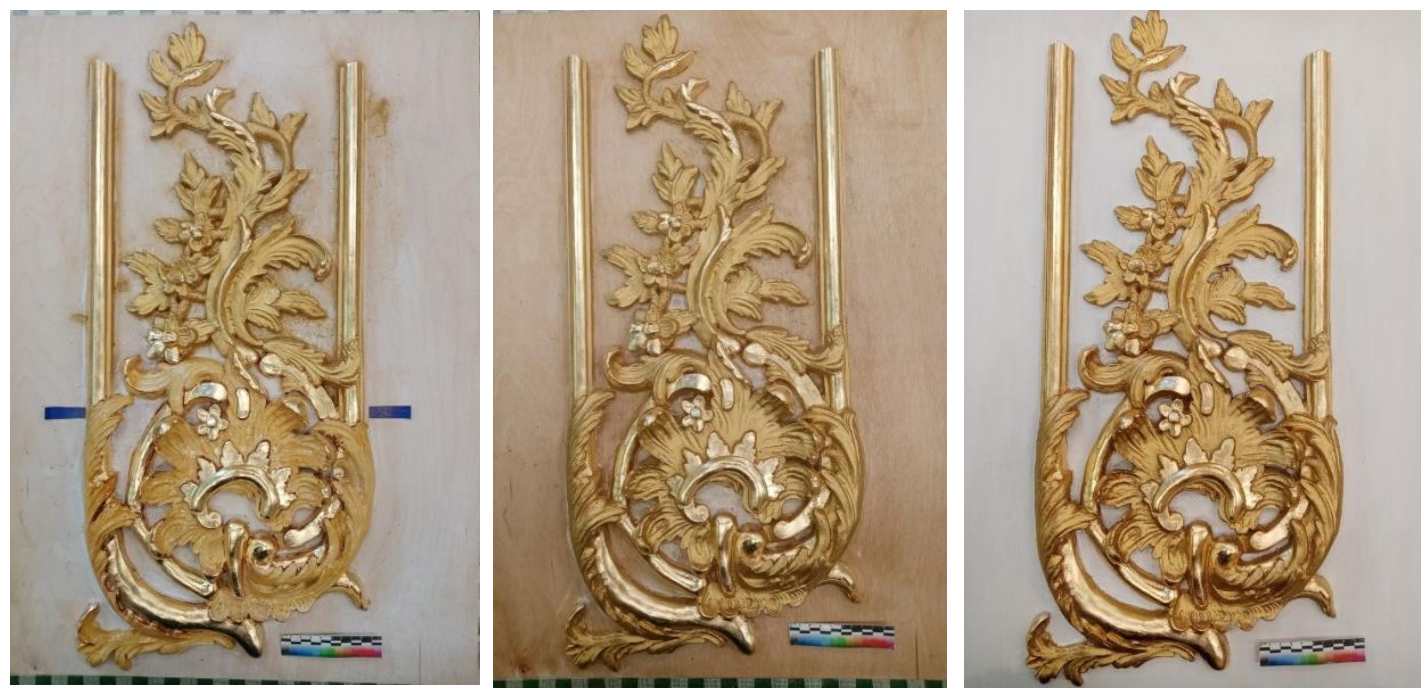

Fig. 62. Application of oil varnish before imitation of matte gilding by bronzing Fig. 63. Imitation of matte gilding by bronzing

Fig. 64. Covering the ornament with protective shellac varnish and painting the stucco decoration by highlighting the background area with white paint 